\title{
The shear stiffness characteristics of four Eocene-to-Jurassic UK stiff clays
}

\author{
A. BROSSE*, R. HOSSEINI KAMAL†, R. J. JARDINE $\ddagger$ and M. R. COOP§
}

\begin{abstract}
A large proportion of the southern UK is underlain by stiff clays. Improving their geotechnical characterisation is important for many current and future infrastructure projects. This paper presents an integrated study of the complex stiffness behaviour of four key medium-plasticity, highly overconsolidated strata: the Gault, Kimmeridge, Oxford and London clays. The latter were deposited between the Jurassic and the Eocene under broadly similar marine conditions. Coordinated programmes of advanced static and dynamic laboratory measurements have been undertaken on high-quality samples, concentrating on samples taken from similar depths at inland sites and including triaxial and hollow cylinder stress path experiments employing high-resolution local strain, multi-axial bender element and resonant column techniques. A new approach was employed to interpret the hollow cylinder experiments and the laboratory measurements are examined in combination with independent field shear wave data. The clays' stiffness characteristics are shown to be markedly anisotropic, pressure dependent and highly non-linear. Synthesis allows key conclusions to be drawn regarding: the relative reliability of alternative measurement approaches; the potential spread of stiffness behaviours between the clays; and whether the clays' varying geological ages and burial depths have any systematic influence on their stiffness characteristics. The results have important geotechnical engineering implications.
\end{abstract}

KEYWORDS: anisotropy; clays; fabric/structure of soils; laboratory tests; stiffness; stress path

\section{INTRODUCTION}

A large proportion of the southern UK is underlain by Triassic to Eocene stiff clays. Their economic importance prompted a study at Imperial College of four mediumplasticity, heavily overconsolidated, Jurassic to Eocene stiff clays that affect nationally important infrastructure. A secondary aim was to investigate whether geological age or burial depth has any systematic influence on mechanical behaviour. Four sampling sites were selected that covered strata deposited in broadly similar environments. The locations and sampling depths were chosen to reduce potential effects of tectonic disturbance and post-depositional weathering, glacial or tree action.

Gasparre et al. (2007a, 2007b) and Hight et al. (2007) report on the London Clay study conducted at the earlier Heathrow Terminal 5 site. The geology and geotechnical characteristics of the Gault, Kimmeridge and Oxford Clay sampling locations' are summarised by Wilkinson (2011), Brosse (2012), Hosseini Kamal (2012) and Hosseini Kamal et al. (2014). Brosse (2012) provides further details on how shear strength anisotropy was investigated in hollow cylinder apparatus (HCA) experiments.

Figures 1-3 summarise the High Cross (Gault), Willow Brook Farm (Kimmeridge) and Elstow (Oxford) stiff clay in situ undrained shear strength and shear modulus $G_{\max }$

Manuscript received 26 October 2015; revised manuscript accepted 26 August 2016. Published online ahead of print 5 October 2016.

Discussion on this paper closes on 1 August 2017, for further details see p. ii.

* Geotechnical Consulting Group, London, UK; formerly Imperial College London, London, UK.

† DNV.GL, London, UK; formerly Imperial College London, London, UK.

† Imperial College London, London, UK.

§ University College London; formerly City University of Hong Kong, Hong Kong, China. profiles. Both features vary over the depth ranges considered due to weathering and occasional hard bands as well as effective stress increases with depth. Table 1 summarises other key characteristics of the Gault, Kimmeridge, Oxford and London clays; for the first three clays Hosseini Kamal et al. (2014) give further information on index properties, composition and mineralogy. The water content profiles generally fall slightly below the plastic limit traces. Hosseini-Kamal et al. (2014) also report suites of oedometer and triaxial compressive shear tests on both reconstituted and high-quality natural samples. They report that, after avoiding or removing as far as possible the potential effects of depositional regime, tectonics, coastal erosion, glacial, periglacial and tree activity, meso-structure has the most important influence on the natural clays' post-yield behaviour. The Oxford Clay, which showed the clearest bedding features but no fissures, developed the highest triaxial compression shear strengths and post-peak brittleness. In contrast, the peak strengths of natural samples of the Gault, Kimmeridge and London clays were strongly affected by their greater fissure intensity. All four soils were markedly brittle in shear, and ring-shear tests confirmed low residual $\phi^{\prime}$ angles. However, no clear correlations were found between age or burial depths and behaviour either in shear or oedometric compression. Current approaches for data normalisation were found to give misleading indications and a more elaborate micro- and meso-fabric framework was required to characterise the effects of natural soil structure.

This paper explores the clays' highly non-linear, anisotropic and pressure-dependent stiffness characteristics, reporting and interpreting high-resolution, locally instrumented, triaxial and HCA tests that cover the full range from very small strains to failure as well as multi-axial bender element and resonant column laboratory measurements in conjunction with in situ shear wave velocity testing. The approach followed extends from that described by Gasparre et al. (2007a, 2007b), Nishimura et al. (2007) and Hight et al. 


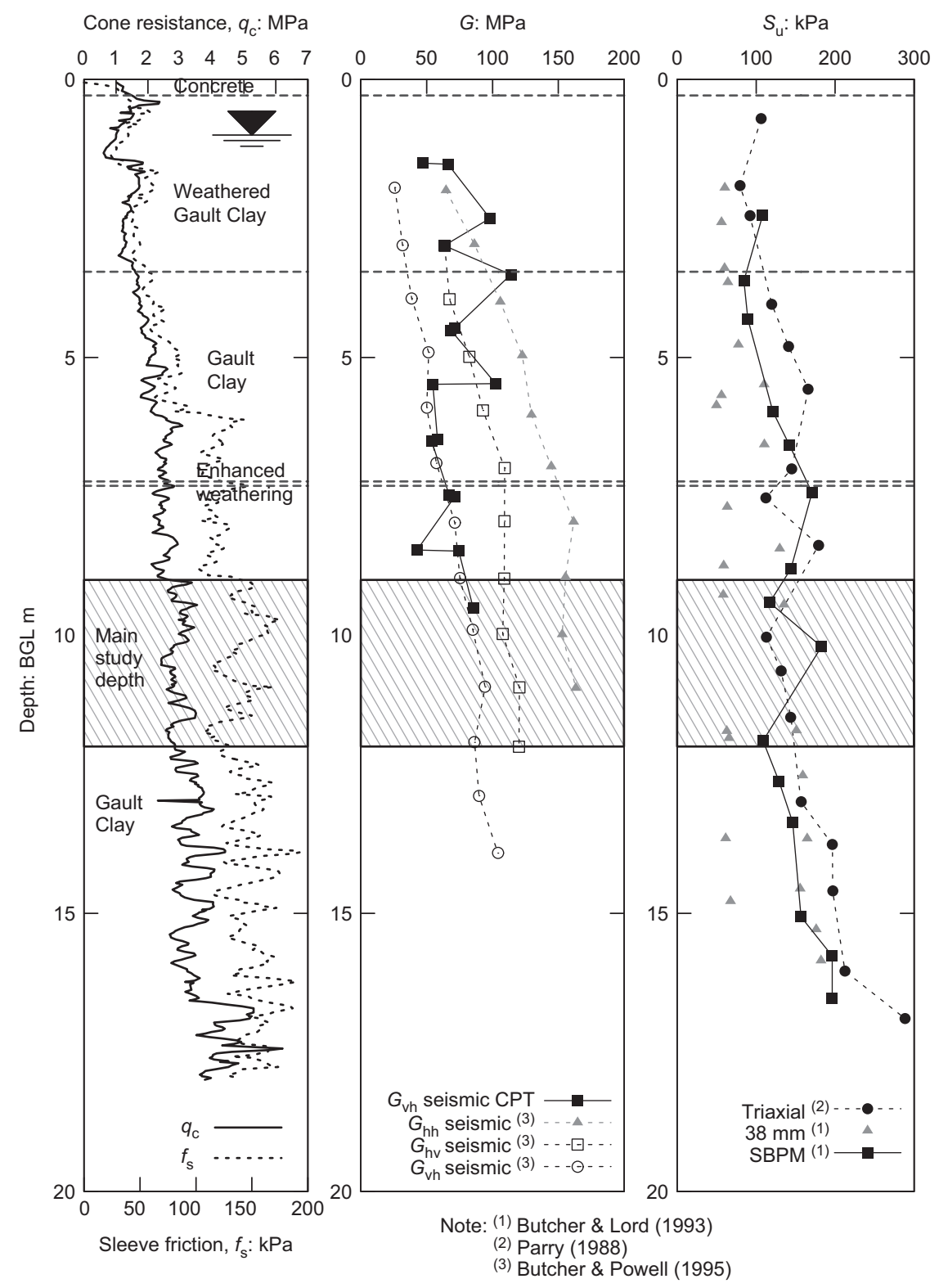

Fig. 1. Gault Clay profile; modified from Hosseini-Kamal et al. (2014)

(2007). Improvements and developments include a new local radial strain arrangement in triaxial tests (Hosseini Kamal, 2012) and a novel approach for interpreting anisotropic non-linear stiffnesses from undrained HCA tests (Brosse, 2012).

The authors consider the experiments identified in Tables 2 and 3 drawn from the broader programmes reported by Hosseini Kamal (2012) and Brosse (2012) and synthesise these with the London Clay measurements by Gasparre (2005), Nishimura (2006), Anh-Minh (2006) and Gasparre et al. $(2007 \mathrm{~b}, 2014)$. The focus is on intact samples retrieved from approximately $10 \mathrm{~m}$ below the top of each clay unit; attention is also given to the behaviour of reconstituted specimens of all four clays and of natural shallower samples taken at around $3.5 \mathrm{~m}$ depth at the Gault Clay test site. While the stiffness characteristics are clearly non-linear over the range of strains relevant to most engineering works, they are reported, for convenience and simplicity, in terms of the cross-anisotropic elastic constitutive framework. Treating the clays as being transversely isotropic allows the Cartesian and cylindrical coordinate axis systems to be used interchangeably, as detailed in the list of notation. The latter assumption is essential to the stiffness framework adopted for interpretation.

\section{APPARATUS AND PROCEDURES \\ Triaxial testing}

Table 2 specifies the triaxial experiments' sampling depths and testing conditions. Most of the programme involved 38 or $100 \mathrm{~mm}$ diameter specimens (with 2:1 height to diameter ratios) in hydraulic Imperial College stress path cells. Recognising the importance of bedding and fissuring, the undrained tests that investigated the natural samples' shearing resistance were conducted principally on $100 \mathrm{~mm}$ diameter specimens. Test duration considerations led to the small-strain stiffness probing programmes on the reconstituted samples and drained natural samples concentrating on $38 \mathrm{~mm}$ dia. specimens. All triaxial tests employed local axial strain measurements, mostly with linear variable differential transformer (LVDT) sensors (Cuccovillo \& Coop, 1997) and others with inclinometers (Jardine et al., 1984). Most apparatus were also fitted with LVDT radial strain measuring devices and bender elements (either platen-mounted or with 


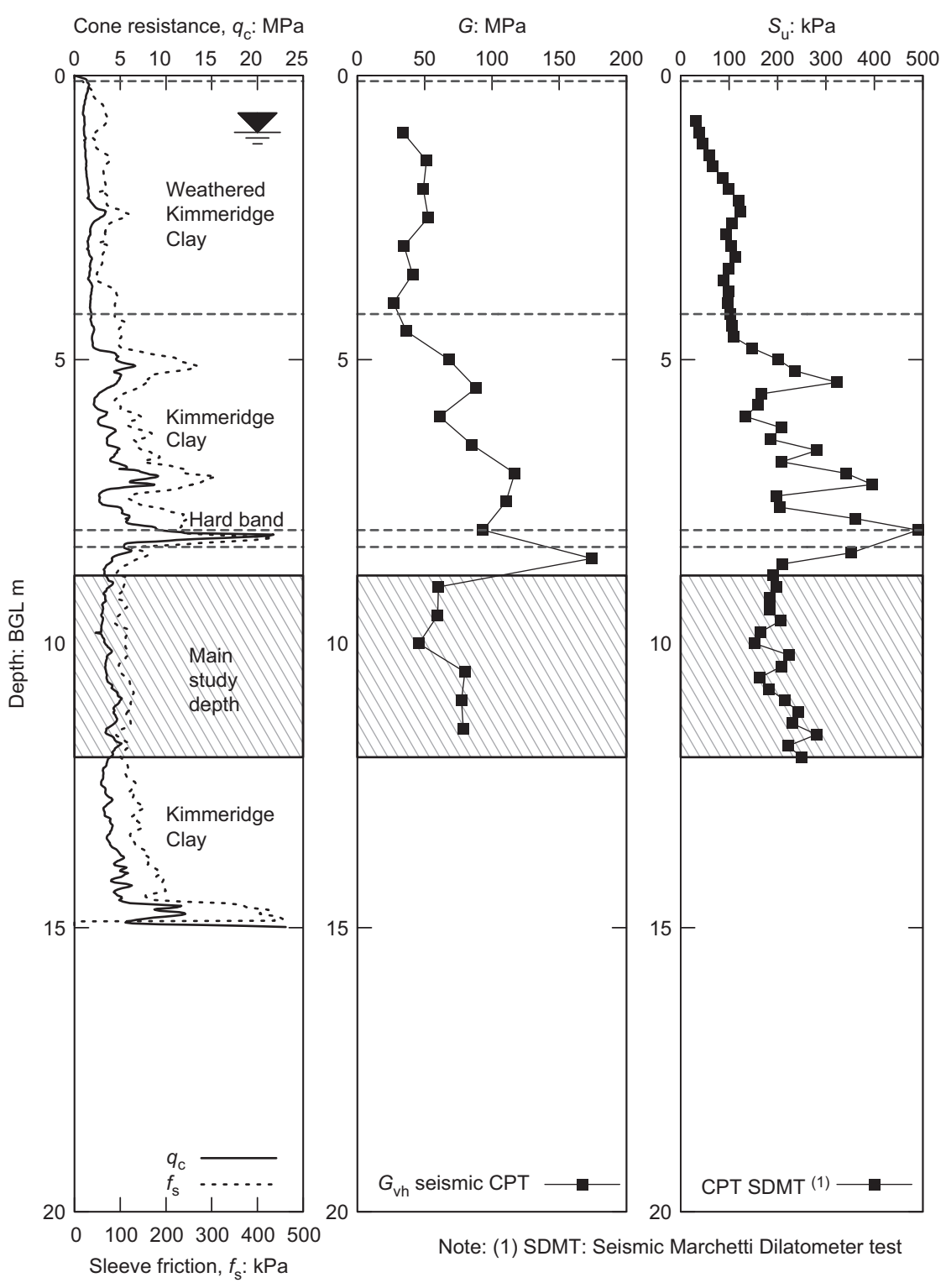

Fig. 2. Kimmeridge Clay profile; modified from Hosseini-Kamal et al. (2014)

a lateral T-configuration similar to that of Pennington et al. (1997) or Kuwano \& Jardine (1998)) as well as mid-height pore pressure transducers to track local pore pressure generation and dissipation.

All tests started by applying a cell pressure sufficient to induce a positive pore pressure. Initial mean effective stress measurements on multiple samples allowed the in situ $p^{\prime}$ and $K_{0}=\sigma_{\mathrm{h} 0}^{\prime} / \sigma_{\mathrm{v} 0}^{\prime}$ values to be estimated, after making allowance for the effects of deviator stress release (see Table 4). Saturation to achieve $B$ values exceeding 0.95 followed. Some specimens were then compressed (or swelled) isotropically to their target $p^{\prime}$ and then sheared undrained. Tests that were intended to start from nominally in situ stresses were taken, after their isotropic stages, along drained constant $p^{\prime}$ paths towards target $K_{0}$ values that were all greater than unity. Trials showed that the $K_{0}$ targets could not be reached without developing axial or volumetric strains that exceeded the limits set (of 0.5 or $1 \%$, respectively), beyond which premature destructuration was expected to occur. Adopting maximum $K_{0}$ values of $1.75 \pm 0.05$, while maintaining the in situ $p^{\prime}$ targets, avoided this difficulty in both triaxial and HCA tests. However, this step led to slightly higher initial vertical and lower horizontal effective stresses being applied in the 'in situ' laboratory tests than had been assessed as acting in situ.

The critical importance (Jardine, 1985; Gasparre et al., 2014) of allowing samples to rest under drained conditions after completing all pore pressure dissipation during reconsolidation was recognised and all shearing stages were delayed until drained axial creep rates had fallen to rates lower than $5 \times 10^{-5} \% / \mathrm{h}$. The shearing rates applied in undrained tests were $0 \cdot 02 \% / \mathrm{h}$, while drained tests were conducted sufficiently slowly for excess pore pressures to dissipate to negligible values.

High sensor resolution and stability are required to track soils' stress-strain responses from their elastic ranges through to ultimate failure. Even though the standard deviations in strain measurements were below $10^{-6}$ and those for stresses below $0.05 \mathrm{kPa}$, multiple readings and averaging were required to establish initial stiffness trends. Sophisticated stress-path control systems are also essential. Bender element tests measured the velocities developed by horizontally and vertically polarised shear waves showing how $G_{\mathrm{hh}}$ and $G_{\mathrm{hv}}$ shear stiffnesses varied throughout testing. In some cases platen mounted bender elements were also used to measure $G_{\mathrm{vh}}$. 


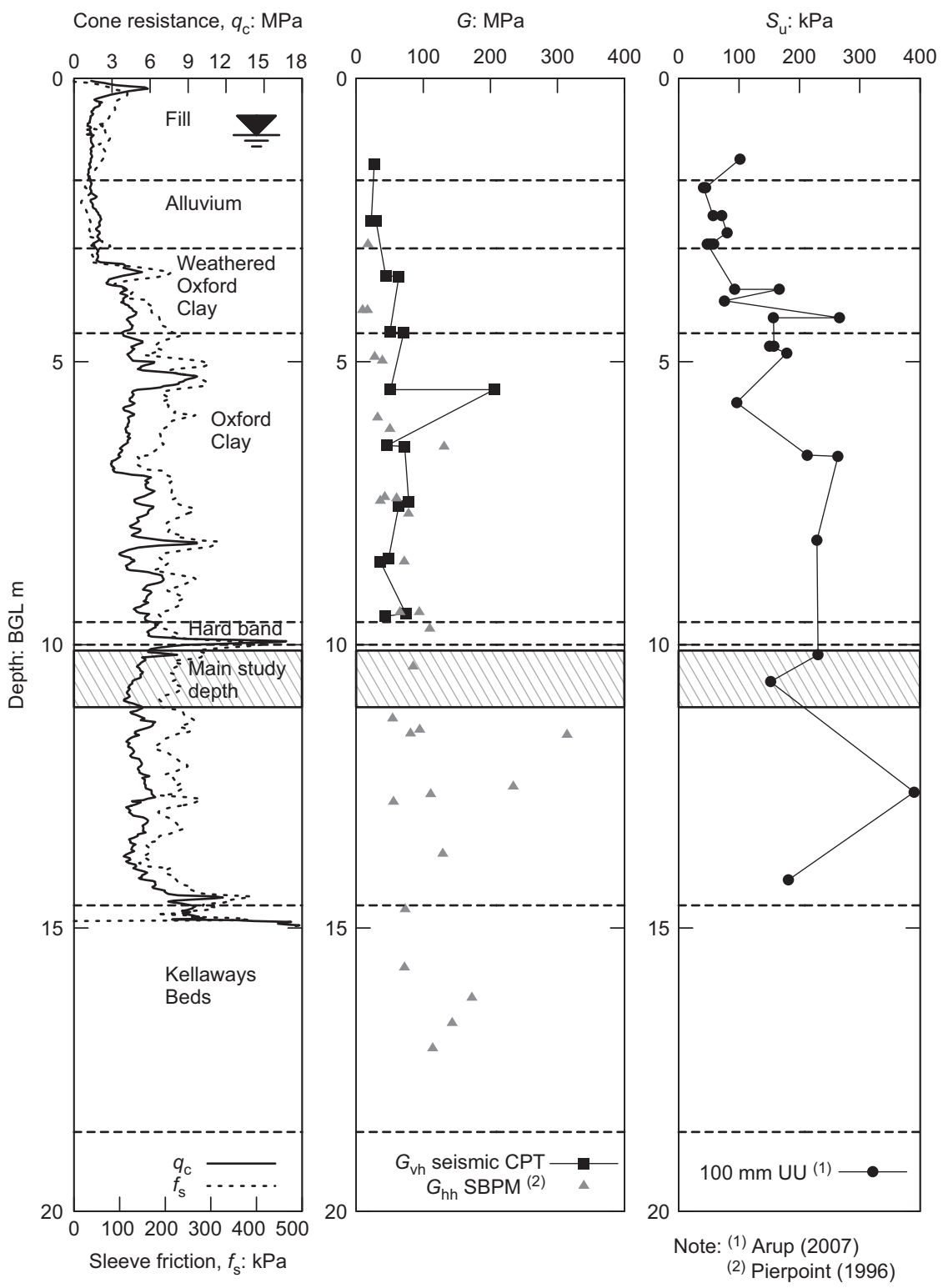

Fig. 3. Oxford Clay profile; modified from Hosseini-Kamal et al. (2014) (SBPM, self-boring pressuremeter)

\section{Hollow cylinder apparatus tests}

Brosse (2012) describes how the non-linear anisotropic stiffness behaviour of the Gault, Kimmeridge and Oxford clays was explored in undrained experiments with both the ICRCHCA (Imperial College resonant column HCA) and the ICHCA II cells, which tested specimens with outside diameters of 72 and $100 \mathrm{~mm}$ and heights of 190 and $200 \mathrm{~mm}$, respectively. The specimens were prepared from high-quality samples by careful trimming and reaming (see Nishimura et al., 2007 or Brosse, 2012) before reconsolidation to the in situ $p^{\prime}$ levels expected at $\approx 10 \mathrm{~m}$ depth and $K_{0} \approx 1 \cdot 75 \pm 0 \cdot 05$, as described above. The shearing stages were more complex than those for triaxial testing. Most tests employed the controlled major principal stress increment direction $\left(\alpha_{d \sigma}\right)$ four-dimensional stress paths defined by Nishimura et al. (2007), although simple shear HCA tests were also conducted. The $\alpha_{d \sigma}$ path tests involved changing $b$ under undrained conditions to 0.5 while keeping $p$ and $q$ constant. After allowing $12 \mathrm{~h}$ for creep, further undrained shearing was initiated with constant $p$ and $b$ while imposing a specified $\alpha_{d \sigma}$ direction that led to the desired final failure value of $\alpha$, the $\sigma_{1}$ axis direction's inclination from the vertical. The simple shear tests were conducted undrained with the axial, radial and circumferential strains kept equal to zero while applying shear straining in the vertical plane. Just as bender element wave velocities were measured throughout the triaxial testing, small-strain non-destructive resonant column tests were conducted with the ICRCHCA equipment to monitor how $G_{\theta z}$ varied during reconsolidation and shearing. Brosse (2012) provides full descriptions of the HCA experiments.

\section{OUTCOMES}

The main focus of this paper is on reporting the stiffness characteristics observed in dynamic and static experiments, concentrating on the Gault, Kimmeridge, Oxford and London clays. Following earlier geophysical and triaxial stiffness studies of the Gault and Oxford clays by Butcher \& Lord (1993), Butcher \& Powell (1995), Hird \& Pierpoint (1997), Pennington et al. (1997) and $\mathrm{Ng}$ et al. (1998), the new work allows direct comparisons to be made between the stiffness properties of the four Jurassic-toEocene clays, which are reported within the framework set out below. 


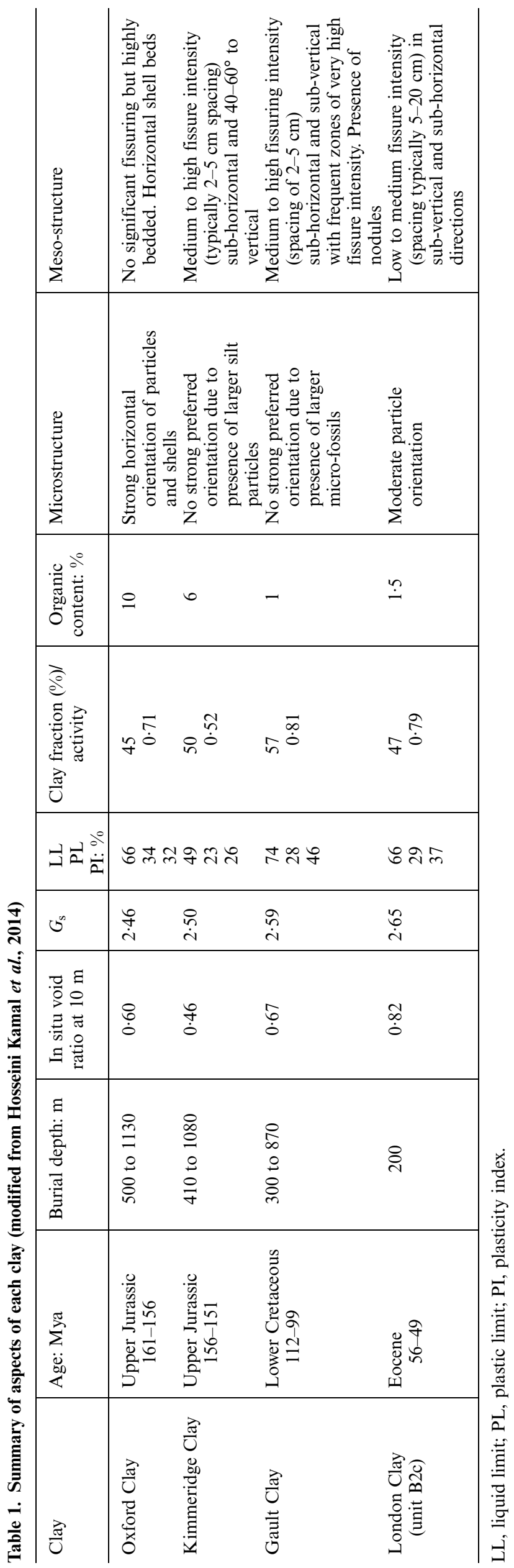

\section{Framework for test interpretation}

Jardine $(1992,2013)$ emphasises that behaviour can only be considered elastic within a very small area of the permissible stress space that is limited by a kinematic hardening $\left(Y_{1}\right)$ true yield surface. The latter is dragged with the current effective stress point, growing and shrinking with $p^{\prime}$ and changing in shape with proximity to the outer $Y_{3}$ surface, which corresponds to the yield surface recognised in classical critical state soil mechanics. Behaviour within $Y_{1}$ can be highly anisotropic. The stiffness anisotropy seen in sands and normally consolidated clays evolves as the applied stress ratio changes, although such changes appear to be less significant for stiff, high overconsolidation ratio (OCR) natural clays. An intermediate kinematic $Y_{2}$ surface was identified that marks: $(a)$ potential changes in strain increment directions; $(b)$ the onset of marked strain-rate or time dependency; and $(c)$ a threshold condition in cyclic tests (as noted by Vucetic, 1994) beyond which permanent strains accumulate significantly. Gasparre et al. (2007a) were able to locate and track the $Y_{1}$ and $Y_{2}$ surfaces for London Clay of various units and depths, confirming that: both scaled with increasing $p^{\prime}$; the behaviour was anisotropic within $Y_{1}$; and the $Y_{2}$ surface marks the limit to the region within which recent 'incoming' stress excursions have no effect on the behaviour developed on common 'outgoing' stress paths. It is recognised that strain rate affects stiffness and that the $Y_{1}$ and $Y_{2}$ surfaces expand when strain rate increases (e.g. see Tatsuoka, 2011). The $Y_{3}$ surface is generally anisotropic and can be located relatively easily for structured soft clays (Smith et al., 1992) but is harder to locate for sands and stiff natural clays (Gasparre et al., 2007a; Kuwano \& Jardine, 2007).

The following sections review the experimental results, starting with the elastic parameter sets evaluated from static and dynamic tests conducted within the $Y_{1}$ region. The limits to the elastic region and the effective-stress dependence of the anisotropic stiffnesses within it are discussed before reviewing the elastic stiffness anisotropy. The response over the entire non-linear range is then considered, starting with undrained triaxial tests before considering the HCA testing that is necessary to investigate stiffness anisotropy over the nonlinear range (Zdravkovic \& Jardine, 1997).

Stiffness anisotropy within the stiff clays' elastic $\mathrm{Y}_{1}$ ranges

Small-strain drained triaxial probing tests were conducted on Gault, Kimmeridge and Oxford Clay samples from nominal in situ stress conditions. Figs 4(a) and 4(b) illustrate a pair of axial loading and unloading probing tests, respectively, conducted on a Kimmeridge rotary core clay sample from $9.45 \mathrm{~m}$ depth, tested after reconsolidation to the in situ $p^{\prime}$ and a $K_{0}$ of $1 \cdot 8$. Figs 5(a) and 5(b) present an equivalent pair of radial probing tests. The key features observed are explained below.

- The data scatter as a result of the very small strains involved. The outputs from the axial strain sensors vary by around $\pm 0 \cdot 0001 \%$, while the radial strain traces scatter by $\pm 0.0003 \%$, reflecting the greater inherent difficulty of measuring radial strains.

- The loading and unloading tests show approximately linear initial behaviour over only very small ranges. The axial tests show clear non-linearity after $\approx 0.0015 \%$ and $0.0025 \%$ in compression and extension, respectively. The radial probing tests remain approximately linear within similar radial strain ranges.

- The initial $\mathrm{d} \sigma_{\mathrm{a}}^{\prime} / \mathrm{d} \varepsilon_{\text {a }}$ gradients are approximately equal under axial loading and unloading, but the radial tests' 
Table 2. Triaxial tests on isotropically consolidated $(q=0)$ and anisotropically consolidated $(q \neq 0)$ specimens of Gault, Kimmeridge and Oxford clays considered in this paper. Note all listed tests ended with undrained shearing in compression, except KN6 which comprised drained axial and radial probing stages

\begin{tabular}{|c|c|c|c|c|c|}
\hline Clay and sample depth & Test & Sample type & Sample diameter: $\mathrm{mm}$ & $p_{0}^{\prime}: \mathrm{kPa}$ & $q: \mathrm{kPa}$ \\
\hline \multicolumn{6}{|l|}{ Gault } \\
\hline $3.5 \mathrm{~m}$ & GN1 & Natural- R & 38 & 160 & -83 \\
\hline $3.5 \mathrm{~m}$ & GN2 & Natural- B & 38 & 70 & 0 \\
\hline $3.5 \mathrm{~m}$ & GN3 & Natural- B & 100 & 142 & -46 \\
\hline $3.5 \mathrm{~m}$ & GN4 & Natural- B & 100 & 200 & 20 \\
\hline $3.5 \mathrm{~m}$ & GN5 & Natural- B & 100 & 350 & 0 \\
\hline $3.5 \mathrm{~m}$ & GN6 & Natural- B & 100 & 400 & 20 \\
\hline $3.5 \mathrm{~m}$ & GN7 & Natural- B & 100 & 500 & 0 \\
\hline $9.8 \mathrm{~m}$ & GN8 & Natural- R & 100 & 250 & 20 \\
\hline $6.5 \mathrm{~m}$ & GN9 & Natural- R & 100 & 125 & -50 \\
\hline $3 \cdot 5 \mathrm{~m}$ & GN10 & Natural-R & 100 & 350 & 0 \\
\hline $12.8 \mathrm{~m}$ & GN11 & Natural- R & 100 & 500 & 0 \\
\hline Mixed & GR1 & Reconstituted & 38 & 500 & 0 \\
\hline Mixed & GR2 & Reconstituted & 38 & 100 & 0 \\
\hline Mixed & GR3 & Reconstituted & 38 & 166 & 0 \\
\hline \multicolumn{6}{|l|}{ Kimmeridge } \\
\hline $9.6 \mathrm{~m}$ & KN1 & Natural- $\mathrm{R}$ & 100 & 185 & -95 \\
\hline $10 \cdot 0 \mathrm{~m}$ & KN2 & Natural- R & 100 & 215 & -170 \\
\hline $11.2 \mathrm{~m}$ & KN3 & Natural- R & 100 & 200 & -105 \\
\hline $10 \cdot 3 \mathrm{~m}$ & KN4 & Natural- $R$ & 100 & 500 & 0 \\
\hline $10.6 \mathrm{~m}$ & KN5 & Natural- R & 38 & 1000 & 0 \\
\hline $9 \cdot 5 \mathrm{~m}$ & KN6 & Natural- R & 38 & 185 & -87 \\
\hline Mixed & KR1 & Reconstituted & 38 & 500 & 0 \\
\hline Mixed & KR2 & Reconstituted & 38 & 100 & 0 \\
\hline Mixed & KR3 & Reconstituted & 38 & 166 & 0 \\
\hline \multicolumn{6}{|l|}{ Oxford } \\
\hline $10 \cdot 0 \mathrm{~m}$ & ON1 & Natural- B & 38 & 360 & 0 \\
\hline $10 \cdot 0 \mathrm{~m}$ & ON2 & Natural- B & 38 & 500 & 0 \\
\hline $10.0 \mathrm{~m}$ & $\mathrm{ON} 3$ & Natural- B & 38 & 590 & 0 \\
\hline $10.0 \mathrm{~m}$ & ON4 & Natural- B & 38 & 650 & 0 \\
\hline $10 \cdot 0 \mathrm{~m}$ & ON4 & Natural- B & 38 & 250 & -100 \\
\hline $10 \cdot 0 \mathrm{~m}$ & ON5 & Natural- B & 100 & 290 & 0 \\
\hline $10 \cdot 0 \mathrm{~m}$ & ON6 & Natural- B & 38 & 400 & 0 \\
\hline $10 \cdot 0 \mathrm{~m}$ & ON5 & Natural- B & 50 & 1300 & 0 \\
\hline Mixed & OR1 & Reconstituted & 38 & 600 & 0 \\
\hline Mixed & OR2 & Reconstituted & 38 & 600 & 0 \\
\hline Mixed & OR3 & Reconstituted & 38 & 50 & 0 \\
\hline Mixed & OR4 & Reconstituted & 50 & 1000 & 0 \\
\hline Mixed & OR5 & Reconstituted & 38 & 310 & 0 \\
\hline
\end{tabular}

$\mathrm{R}$, rotary natural sample; $\mathrm{B}$, block natural sample.

local gradients, which are here termed $A=\mathrm{d} \sigma_{\mathrm{r}}^{\prime} / \mathrm{d} \varepsilon_{\mathrm{r}}$, are significantly softer on unloading than loading.

- Consistent ratios develop between the strain components in each test; $\mathrm{d} \varepsilon_{\mathrm{r}} / \mathrm{d} \varepsilon_{\mathrm{a}} \approx-0.22$ under purely axial loading, while the ratio increases to $\approx-0.55$ under radial loading.

The effective stress cross-anisotropic compliance relationships can be expressed as equation (1), provided that the increments: $(a)$ remain within the $Y_{1}$ locus and $(b)$ do not affect the hypo-elastic compliance terms significantly

$$
\delta \varepsilon_{\mathrm{h}}=-\frac{v_{\mathrm{vh}}^{\prime}}{E_{\mathrm{v}}^{\prime}} \delta \sigma_{\mathrm{v}}^{\prime}
$$

from which $E_{\mathrm{v}}^{\prime}$ and $v_{\mathrm{vh}}^{\prime}$ can be determined. Noting that the axial strains show less scatter than the radial, the Poisson ratio is measured less reliably than $E_{\mathrm{v}}^{\prime}$.

Radial probing tests performed with $\delta \sigma_{\mathrm{v}}^{\prime}=0$, lead to a similarly reduced set of equations which can be manipulated as shown by Kuwano (1999). The relationship between radial

$$
\left\{\begin{array}{l}
\delta \varepsilon_{x} \\
\delta \varepsilon_{y} \\
\delta \varepsilon_{z} \\
\delta \gamma_{x y} \\
\delta \gamma_{y z} \\
\delta \gamma_{z x}
\end{array}\right\}=\left[\begin{array}{cccccc}
1 / E_{\mathrm{h}}^{\prime} & -v_{\mathrm{hh}}^{\prime} / E_{\mathrm{h}}^{\prime} & -v_{\mathrm{vh}}^{\prime} / E_{\mathrm{v}}^{\prime} & 0 & 0 & 0 \\
-v_{\mathrm{hh}}^{\prime} / E_{\mathrm{h}}^{\prime} & 1 / E_{\mathrm{h}}^{\prime} & -v_{\mathrm{vh}}^{\prime} / E_{\mathrm{v}}^{\prime} & 0 & 0 & 0 \\
-v_{\mathrm{hv}}^{\prime} / E_{\mathrm{h}}^{\prime} & -v_{\mathrm{hv}}^{\prime} / E_{\mathrm{h}}^{\prime} & 1 / E_{\mathrm{v}}^{\prime} & 0 & 0 & 0 \\
0 & 0 & 0 & 1 / G_{\mathrm{hv}} & 0 & 0 \\
0 & 0 & 0 & 0 & 1 / G_{\mathrm{vh}} & 0 \\
0 & 0 & 0 & 0 & 0 & 1 / G_{\mathrm{hh}}
\end{array}\right]\left\{\begin{array}{c}
\delta \sigma_{x}^{\prime} \\
\delta \sigma_{y}^{\prime} \\
\delta \sigma_{z}^{\prime} \\
\delta \tau_{x y} \\
\delta \tau_{y z} \\
\delta \tau_{z x}
\end{array}\right\}
$$

For axial tests performed within $Y_{1}$ and with $\delta \sigma_{\mathrm{h}}^{\prime}=0$, the relationship reduces to

$$
\delta \varepsilon_{\mathrm{v}}=\frac{1}{E_{\mathrm{v}}^{\prime}} \delta \sigma_{\mathrm{v}}^{\prime}
$$

effective stress change and radial strain in such tests can be combined with bender element shear wave velocity 
Table 3. Hollow cylinder tests conducted on intact samples of all four clays; after Brosse (2012)

\begin{tabular}{|c|c|c|c|c|c|c|c|c|}
\hline \multirow[t]{2}{*}{ Test reference } & \multirow[t]{2}{*}{ Sample type } & \multirow{2}{*}{$\begin{array}{l}\text { Specimen } \\
\text { depth: } \\
\text { mBGL }\end{array}$} & \multirow[t]{2}{*}{ Apparatus } & \multirow[t]{2}{*}{ Type of test } & \multicolumn{2}{|c|}{ Initial stresses } & \multirow{2}{*}{$\begin{array}{c}\alpha \text { at } q_{\text {peak }}: \\
\text { Degree }\end{array}$} & \multirow[t]{2}{*}{$b$} \\
\hline & & & & & $p_{0}^{\prime}: \mathrm{kPa}$ & $q_{0}: \mathrm{kPa}$ & & \\
\hline \multicolumn{9}{|l|}{ Oxford Clay } \\
\hline $\mathrm{OA} 0005$ & Block & 10 & ICRCHCA & Constant $\alpha_{\mathrm{d} \sigma}$ & 250 & -130 & 0 & $0 \cdot 5$ \\
\hline OA2305 & Block & 10 & ICRCHCA & Constant $\alpha_{\mathrm{d} \sigma}$ & 250 & -130 & 22 & $0 \cdot 5$ \\
\hline OA4505 & Block & 10 & ICRCHCA & Constant $\alpha_{\mathrm{d} \sigma}$ & 252 & -125 & 43 & $0 \cdot 5$ \\
\hline OA6705 & Block & 10 & ICRCHCA & Constant $\alpha_{\mathrm{d} \sigma}$ & 250 & -130 & 69 & $0 \cdot 5$ \\
\hline OA9005 & Block & 10 & ICRCHCA & Constant $\alpha_{\mathrm{d} \sigma}$ & 252 & -125 & 90 & $0 \cdot 5$ \\
\hline OA0005* & Block & 10 & ICRCHCA & Constant $\alpha_{\mathrm{d} \sigma}$ & 252 & -125 & 0 & $0 \cdot 5$ \\
\hline OASS & Block & 10 & ICRCHCA & Simple shear & 250 & -130 & - & - \\
\hline \multicolumn{9}{|c|}{ Kimmeridge Clay } \\
\hline KA0005 & Rotary core & $11 \cdot 5$ & ICHCA II & Constant $\alpha_{\mathrm{d} \sigma}$ & 186 & -97 & 0 & $0 \cdot 5$ \\
\hline KA2305 & Rotary core & $11 \cdot 2$ & ICHCA II & Constant $\alpha_{\mathrm{d} \sigma}$ & 186 & -97 & 21 & $0 \cdot 5$ \\
\hline KA4505 & Rotary core & $11 \cdot 5$ & ICHCA II & Constant $\alpha_{\mathrm{d} \sigma}$ & 186 & -97 & 40 & $0 \cdot 5$ \\
\hline KA 6705 & Rotary core & $11 \cdot 9$ & ICHCA II & Constant $\alpha_{\mathrm{d} \sigma}$ & 186 & -97 & 63 & $0 \cdot 5$ \\
\hline KA9005 & Rotary core & $11 \cdot 7$ & ICHCA II & Constant $\alpha_{\mathrm{d} \sigma}$ & 186 & -97 & 90 & $0 \cdot 5$ \\
\hline KT9005 & Rotary core & $8 \cdot 6$ & ICHCA II & Constant $\alpha_{\mathrm{d} \sigma}$ & 186 & -97 & 90 & $0 \cdot 5$ \\
\hline KASS & Rotary core & $9 \cdot 0$ & ICRCHCA & Simple shear & 186 & -97 & - & - \\
\hline \multicolumn{9}{|l|}{ Gault Clay } \\
\hline GA0005 & Rotary core & $9 \cdot 5$ & ICRCHCA & Constant $\alpha_{\mathrm{d} \sigma}$ & 163 & -85 & 0 & $0 \cdot 5$ \\
\hline GA2305 & Rotary core & $9 \cdot 8$ & ICRCHCA & Constant $\alpha_{\mathrm{d} \sigma}$ & 163 & -85 & 21 & $0 \cdot 5$ \\
\hline GA4505 & Rotary core & $11 \cdot 8$ & ICRCHCA & Constant $\alpha_{\mathrm{d} \sigma}$ & 163 & -85 & 39 & $0 \cdot 5$ \\
\hline GA6705 & Rotary core & $10 \cdot 6$ & ICRCHCA & Constant $\alpha_{\mathrm{d} \sigma}$ & 163 & -85 & 65 & $0 \cdot 5$ \\
\hline GA9005 & Rotary core & $10 \cdot 3$ & ICRCHCA & Constant $\alpha_{\mathrm{d} \sigma}$ & 163 & -85 & 90 & $0 \cdot 5$ \\
\hline GA2305* & Rotary core & $12 \cdot 5$ & ICRCHCA & Constant $\alpha_{\mathrm{d} \sigma}$ & 163 & -85 & 20 & $0 \cdot 5$ \\
\hline GASS & Rotary core & $10 \cdot 9$ & ICRCHCA & Simple shear & 163 & -85 & - & - \\
\hline \multicolumn{9}{|l|}{ London Clay } \\
\hline LA0005 & Block & $10 \cdot 5$ & ICRCHCA & Constant $\alpha_{\mathrm{d} \sigma}$ & 323 & -165 & 0 & $0 \cdot 5$ \\
\hline LA2305 & Block & $10 \cdot 5$ & ICRCHCA & Constant $\alpha_{\mathrm{d} \sigma}$ & 323 & -165 & 23 & $0 \cdot 5$ \\
\hline LA4505 & Block & $10 \cdot 5$ & ICRCHCA & Constant $\alpha_{\mathrm{d} \sigma}$ & 323 & -165 & 48 & $0 \cdot 5$ \\
\hline LA6705 & Block & $10 \cdot 5$ & ICRCHCA & Constant $\alpha_{\mathrm{d} \sigma}$ & 323 & -165 & 67 & $0 \cdot 5$ \\
\hline LA9005 & Block & $10 \cdot 5$ & ICRCHCA & Constant $\alpha_{\mathrm{d} \sigma}$ & 323 & -165 & 90 & $0 \cdot 5$ \\
\hline LASS & Block & $10 \cdot 5$ & ICRCHCA & Simple shear & 323 & -165 & - & - \\
\hline
\end{tabular}

measurements that give dynamic $G_{\mathrm{hh}}$ values so that

$$
\begin{gathered}
E_{\mathrm{h}}^{\prime}=-\frac{4 A G_{\mathrm{hh}}}{A+2 G_{\mathrm{hh}}} \\
v_{\mathrm{hh}}^{\prime}=\frac{A-2 G_{\mathrm{hh}}}{A+2 G_{\mathrm{hh}}}
\end{gathered}
$$

where $A=E_{\mathrm{h}} /\left(1-v_{\mathrm{hh}}\right)$ (see Appendix 1). The remaining effective stress Poisson ratio term is then $v_{\mathrm{hv}}^{\prime}=v_{\mathrm{vh}}^{\prime} E_{\mathrm{h}}^{\prime} / E_{\mathrm{v}}^{\prime}$ and the compliance matrix is completed by using bender elements or resonant column techniques to determine $G_{\mathrm{hv}}$.

Noting that the numerator of equation (5) involves subtracting two quantities of broadly similar magnitudes, the effects of measurement errors on the $v_{\text {hh }}^{\prime}$ evaluation are more severe than those for $v_{\mathrm{hv}}^{\prime}$. In the same way the $E_{\mathrm{h}}^{\prime}$ outcomes are liable to greater error margins that those for $G_{\mathrm{hv}}$ or $E_{\mathrm{v}}^{\prime}$ because equation (4) requires: an additional 'stiffness' measurement; input from the more scattered radial strains; and an additional assumption that stiffness is strain rate independent. The latter is critical to combining the static $A$ and dynamic $G_{\mathrm{hh}}$ measurements in equations (4) and (5).

In principle, the above effective stress parameters can be manipulated further to find undrained elastic vertical and horizontal stiffnesses through equations (6) and (7) from Lings (2001).

$$
\begin{aligned}
& E_{\mathrm{v}}^{\mathrm{u}}=\frac{E_{\mathrm{v}}^{\prime}\left[2\left(1-v_{\mathrm{hh}}^{\prime}\right) E_{\mathrm{v}}^{\prime}+\left(1-4 v_{\mathrm{vh}}^{\prime}\right) E_{\mathrm{v}}^{\prime}\right]}{2\left(1-v_{\mathrm{hh}}^{\prime}\right) E_{\mathrm{v}}^{\prime}-4\left(v_{\mathrm{vh}}^{\prime}\right)^{2} E_{\mathrm{h}}^{\prime}} \\
& E_{\mathrm{h}}^{\mathrm{u}}=\frac{E_{\mathrm{h}}^{\prime}\left[2\left(1-v_{\mathrm{hh}}^{\prime}\right)\left(E_{\mathrm{v}}^{\prime}\right)^{2}+\left(1-4 v_{\mathrm{vh}}^{\prime}\right) E_{\mathrm{v}}^{\prime} E_{\mathrm{h}}^{\prime}\right]}{\left[1-\left(v_{\mathrm{hh}}^{\prime}\right)^{2}\right]\left(E_{\mathrm{v}}^{\prime}\right)^{2}+\left(1-2 v_{\mathrm{vh}}^{\prime}-2 v_{\mathrm{vh}}^{\prime} v_{\mathrm{hh}}^{\prime}\right) E_{\mathrm{v}}^{\prime} E_{\mathrm{h}}^{\prime}-\left(v_{\mathrm{vh}}^{\prime}\right)^{2}\left(E_{\mathrm{h}}^{\prime}\right)^{2}}
\end{aligned}
$$

However, the computed values are highly sensitive to any errors made in the stresses and strains, particularly in the case of $E_{\mathrm{h}}^{\mathrm{u}}$. As summarised in Appendix 2, Brosse (2012) showed how the compliance relationship given in equation (1) may be simplified and applied to undrained HCA tests to give clearer measurements of anisotropy, delivering more direct measurements of $E_{\mathrm{h}}^{\mathrm{u}}$ than equation (7), as well as direct measurements of $E_{\mathrm{v}}^{\mathrm{u}}$ and $G_{\mathrm{hv}}$. Appendix 2 also summarises how the four-dimensional stress and strain HCA data may be manipulated and processed to reduce scatter and improve data consistency. These steps were applied herein to undrained stress path and simple shear HCA tests on the Gault, Kimmeridge and Oxford clays and Nishimura's (2006) London Clay HCA experiments. Most HCA experiments relied on external or platen-to-platen strain measurements. Although every feasible step was taken to allow for effects of apparatus compliance and eliminate bedding errors, the representativeness of the elastic parameters interpreted from the HCA tests is less certain.

A summary is given in Table 4 of the stiffness parameters found for all four clays in drained triaxial probing and resonant column tests conducted under the in situ conditions expected $\approx 10 \mathrm{~m}$ below each clay stratum's upper surface. Note that the London Clay was tested at higher effective stresses than the others because it was overlain at the rotary borehole location by $6 \mathrm{~m}$ of Quaternary river terrace gravels 


\begin{tabular}{|c|c|c|c|c|}
\hline 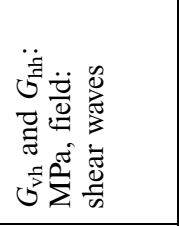 & 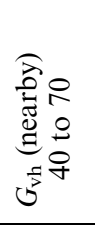 & $\begin{array}{l}\infty \\
0 \\
0 \\
0 \\
1 \\
0 \\
0\end{array}$ &  & 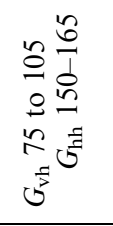 \\
\hline 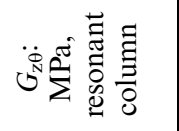 & $\underbrace{0}_{\infty}$ & 8 & 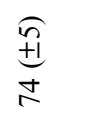 & $\underbrace{\stackrel{f}{+1}}_{\infty}$ \\
\hline 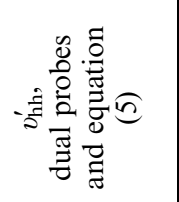 & $\stackrel{+}{m}$ & $\frac{0}{0}$ & ஜ̊ & $\dot{0}$ \\
\hline - & ర్ర & $\stackrel{n}{0}$ & $\begin{array}{l}T \\
0\end{array}$ & $\stackrel{n}{n}$ \\
\hline 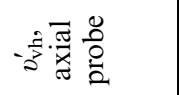 & $\underset{\hat{\theta}}{0}$ & $\underset{ஸ}{0}$ & $\stackrel{\Uparrow}{0}$ & $\hat{0}$ \\
\hline 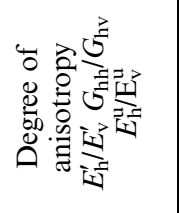 & 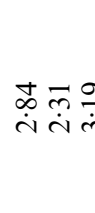 & 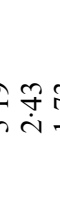 &  & 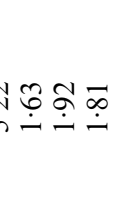 \\
\hline 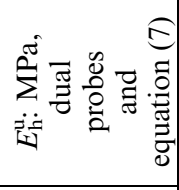 & $\widehat{్}$ & $\underset{f}{\stackrel{f}{f}}$ & \&్ర & ల \\
\hline 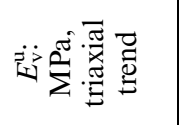 & $\stackrel{尺}{\curvearrowright}$ & 守 & $\approx$ & $\underset{\infty}{\infty}$ \\
\hline  & $\stackrel{\overbrace{}}{\sim}$ & $\bar{\beth}$ & $\stackrel{\varrho}{=}$ & $\cong$ \\
\hline 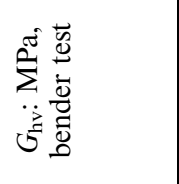 & $\stackrel{n}{\varrho}$ & 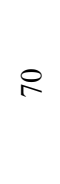 & in & 8 \\
\hline 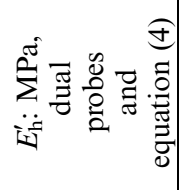 & $\vec{\pi}$ & $\stackrel{\partial}{\vec{\nu}}$ & 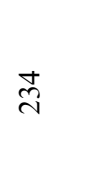 & तิ \\
\hline 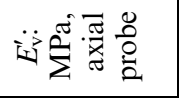 & $\stackrel{m}{=}$ & \& & $\stackrel{n}{n}$ & I \\
\hline ש̈ & 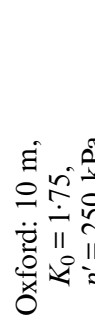 & 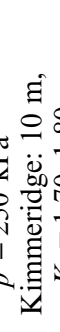 & 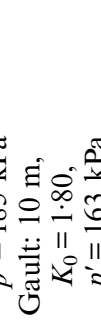 & 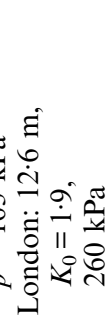 \\
\hline
\end{tabular}

which had been removed 70 years earlier at the block sampling area (Hight et al., 2007). The nearest group of triaxial tests reported by Gasparre et al. (2007b) was from $12.6 \mathrm{~m}$ below ground level at the rotary location (or $6.6 \mathrm{~m}$ depth at the block area), while the HCA tests described by Brosse (2012) came from block samples taken at $\approx 10 \mathrm{~m}$ depth.

Table 4 also lists ranges for the field $G_{\mathrm{vh}}$ and $G_{\mathrm{hh}}$ values interpreted from shear wave velocity measurements made by seismic cone penetration (SCPT), dilatometer (SDMT), down-hole or cross-hole techniques at the four sites, as presented in Figs 1-3 and detailed by Hight et al. (2007), Hosseini Kamal (2012) and Brosse (2012). The vertical Young's moduli and Poisson ratios represent averages from both loading and extension tests. Best estimate values of the vertical elastic undrained stiffness $E_{\mathrm{v}}^{\mathrm{u}}$ from the triaxial tests and bender element $G_{\mathrm{hh}}$ and $G_{\mathrm{hv}}\left(=G_{\mathrm{vh}}\right)$ moduli are also listed, which were derived from all the tests listed in Table 2. The values tabulated for Gault, Kimmeridge and Oxford clays were derived by substituting the in situ $p^{\prime}$ values into best-fitting relationships established between $E_{\mathrm{v}}^{\mathrm{u}}, G_{\mathrm{hh}}$ and $G_{\mathrm{hv}}$ and $p^{\prime}$ that were derived, as shown later, from multiple individual direct measurements. This approach reduced the impact of scatter. Estimates for $E_{\mathrm{h}}^{\mathrm{u}}$ derived from equation (7) are also shown that are acknowledged to be less certain than those for any other parameter for the reasons described above. In some cases multiple measurements were made of the same quantity; for example at least six resonant column $G_{\mathrm{z} \theta}$ values were available for all strata except the Kimmeridge Clay and averages are given along with standard deviations.

Table 4 details the marked elastic stiffness anisotropy of all four clays, which has been quantified by the three ratios $G_{\mathrm{hh}} / G_{\mathrm{hv}}, E_{\mathrm{h}}^{\prime} / E_{\mathrm{v}}^{\prime}$ and $E_{\mathrm{h}}^{\mathrm{u}} / E_{\mathrm{v}}^{\mathrm{u}}$. Fig. 6 plots these ratios for the natural clay samples under in situ stresses, against each stratum's estimated prior maximum depth of burial, adding Gasparre et al.'s (2007b) tests on London Clay unit $B_{2(\mathrm{c})}$. The clays' burial depths increase systematically with their ages, so it is not possible to separate the potential influences of age and depth. However, over the 200 to $500 \mathrm{~m}$ depth ranges considered their combined influence on the anisotropy ratios appears to be modest or even absent. Because no clear trends with depth can be identified, average values are indicated on the figure, which indicate different degrees of anisotropy depending on the ratio considered. These are 1.97 for $G_{\mathrm{hh}} / G_{\mathrm{hv}}, 2.51$ for $E_{\mathrm{h}}^{\prime} / E_{\mathrm{v}}^{\prime}$ and 3.36 for $E_{\mathrm{h}}^{\mathrm{u}} / E_{\mathrm{v}}^{\mathrm{u}}$. The $G_{\mathrm{hh}} / G_{\mathrm{hv}}$ ratios, which are based on directly measured stiffnesses, show less scatter in Fig. 6 than those for the Young's moduli, where the horizontal values had to be derived through the more convoluted process described in Appendix 1.

The data in Table 4 for the Gault Clay may be compared with the values reported by Lings et al. (2000) from specimens sampled at slightly shallower depths $(6-8 \mathrm{~m})$ at the same site, but tested at similar estimated in situ stress levels to those employed by the authors. Lings et al.'s normalised plots imply $E_{\mathrm{v}}^{\prime}=90 \mathrm{MPa}, E_{\mathrm{h}}^{\prime}=356 \mathrm{MPa}$, $G_{\mathrm{hv}}=83 \mathrm{MPa}$ and $G_{\mathrm{hh}}=186 \mathrm{MPa}$ under the authors' $p^{\prime}=163 \mathrm{kPa}$ testing conditions that are significantly stiffer than those listed in Table 4 . The Poisson ratios reported by Lings et al. were $v_{\mathrm{vh}}^{\prime}=0$ and $v_{\mathrm{hh}}^{\prime}=-0.04( \pm 0 \cdot 05)$ and are also lower than the 0.20 and 0.06 values derived from the tests in the present study. The different sampling depths and degrees of suction imposed by vegetation could have led to some of the dispersion between the two data sets, as could variations in measurement technique. The poorer strain resolution available in the earlier study led to Young's moduli being derived by differentiating data curve fits rather than being taken from direct measurements and could also have affected 


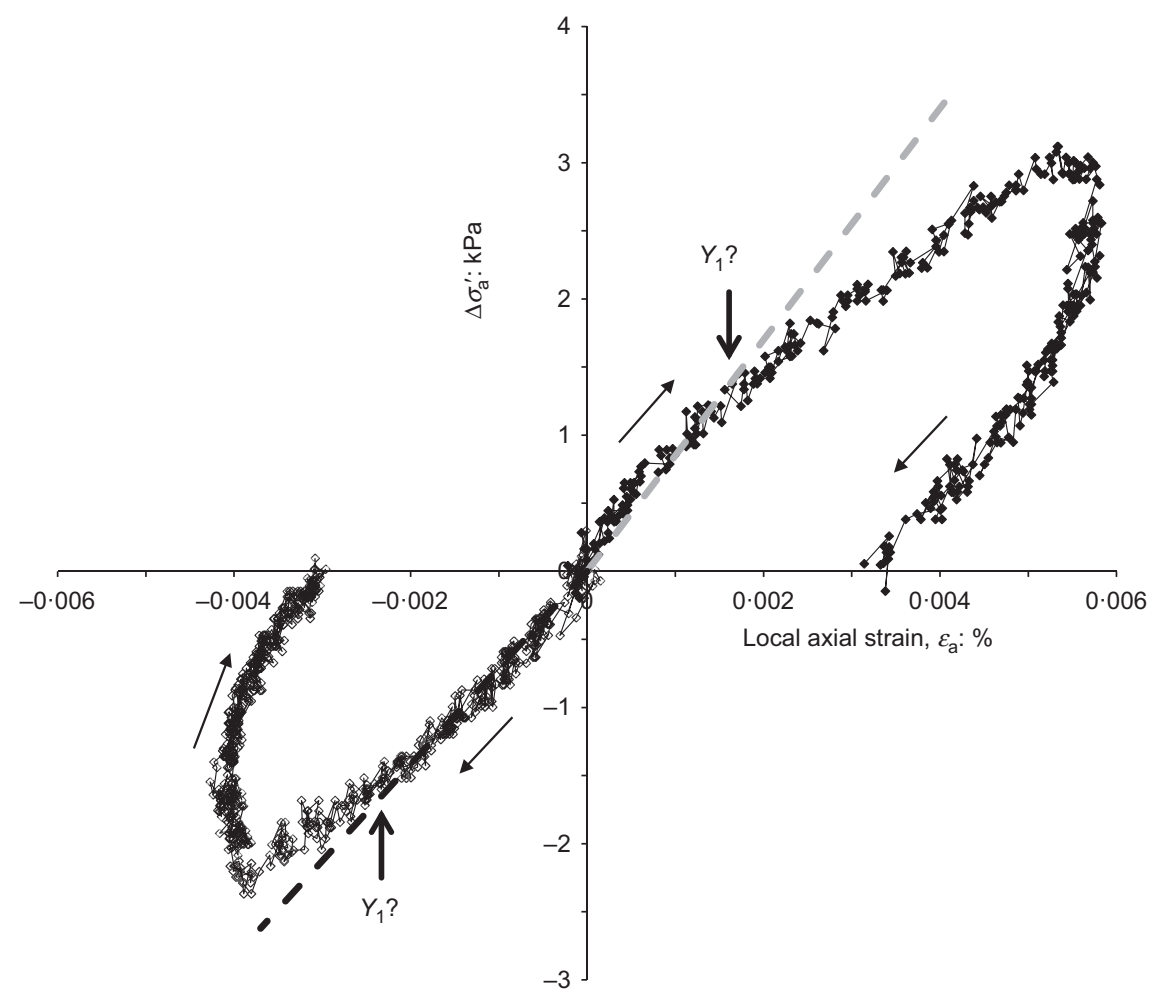

(a)

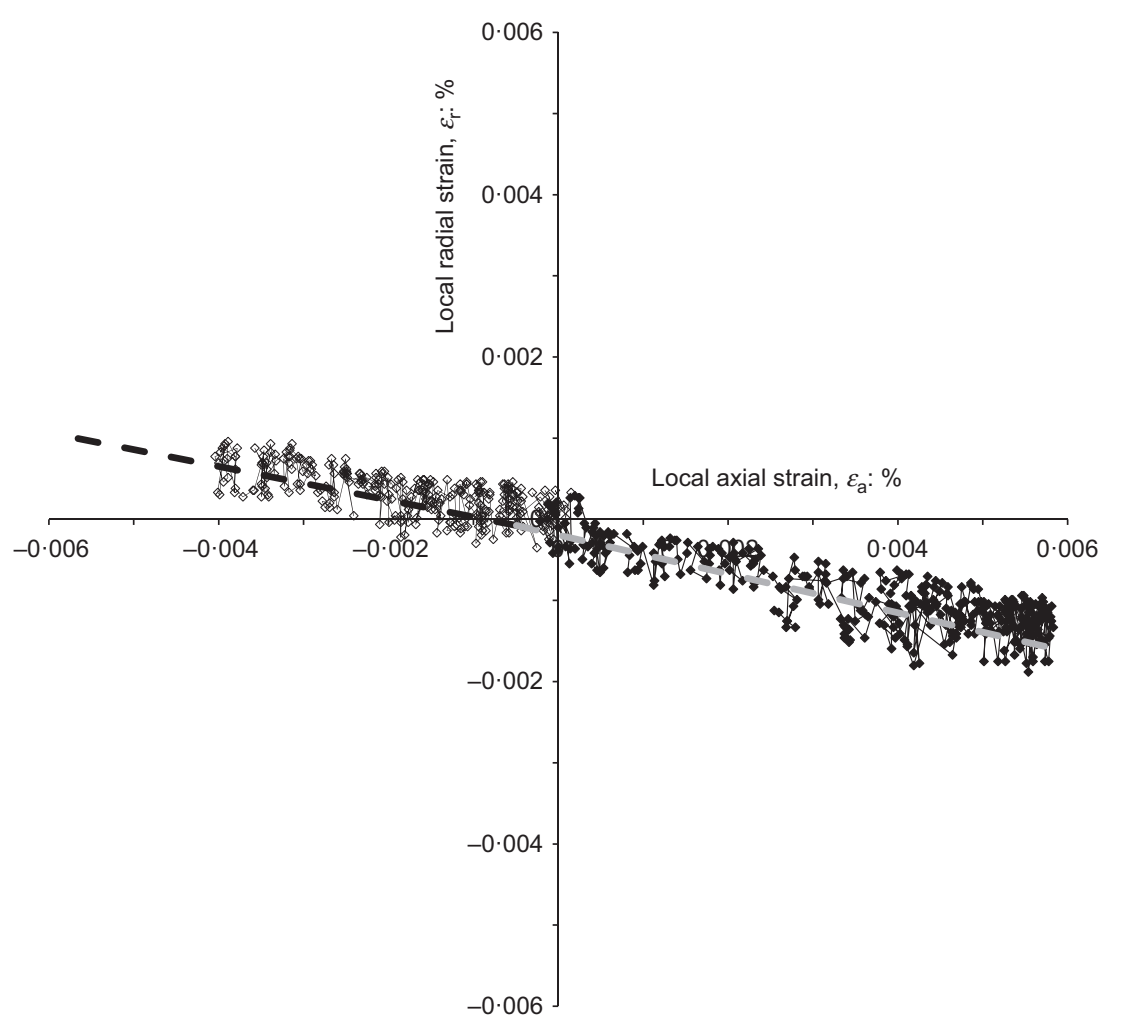

(b)

Fig. 4. Drained axial stress probing test on Kimmeridge Clay: (a) axial strain response; (b) radial strain response

the Poisson ratios. Nevertheless, the degrees of anisotropy are broadly comparable between the data sets with $G_{\mathrm{hh}} / G_{\mathrm{hv}}$ ratios of 1.93 from the present study and $2 \cdot 25$ from Lings et al., and $E_{\mathrm{h}}^{\prime} / E_{\mathrm{hv}}^{\prime}$ ratios of $3 \cdot 1$ and $4 \cdot 0$, respectively.
Relationships between elastic stiffnesses and mean effective stress level

Gasparre et al. (2007a) report multiple probing tests over a $50 \mathrm{~m}$ deep London Clay profile, noting how the elastic 


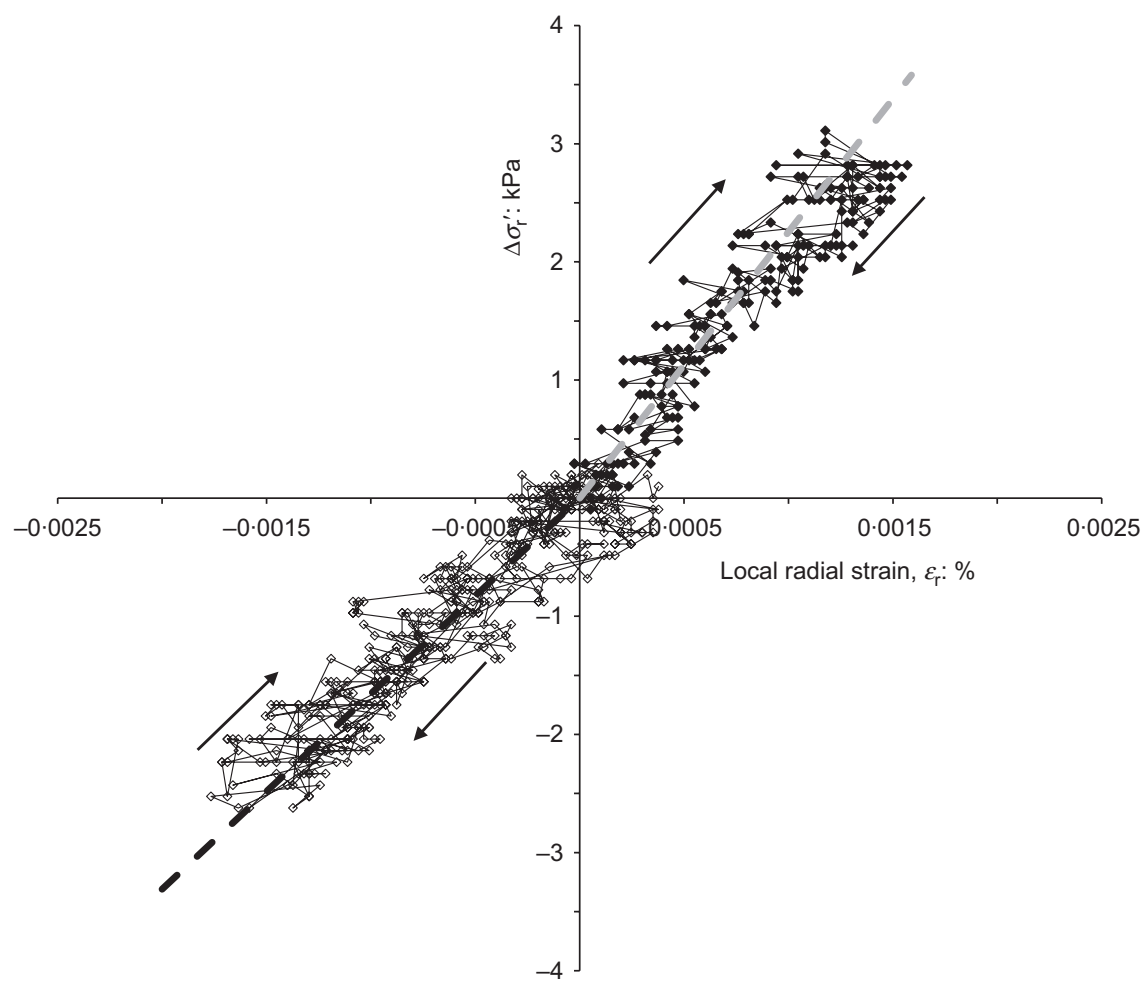

(a)

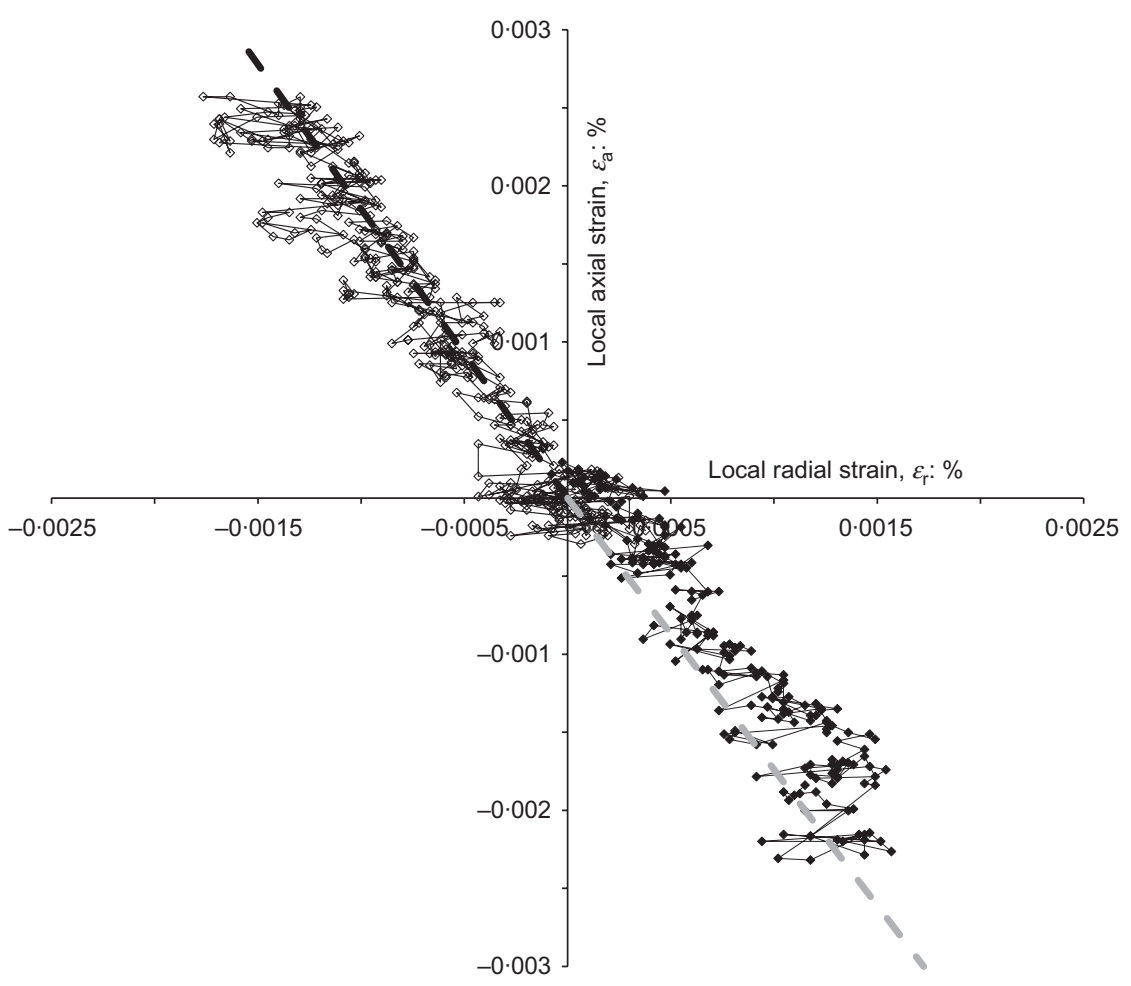

(b)

Fig. 5. Drained radial stress probing test on Kimmeridge Clay: (a) radial strain response; (b) axial strain response

stiffnesses and their anisotropy varied with depth. One key finding was that the in situ and laboratory stiffnesses that had developed over geological time tended to correlate almost linearly with the mean in situ stress $p_{0}^{\prime}$. However, when effective stress changes were applied in the laboratory their effect on the clay's stiffness was far less significant and the
$N$ values in the power-law relationships between stiffness and $p^{\prime}$ were far lower. This feature became still clearer, when allowance was made for void ratio changes

$$
G_{0}=f(e) M P_{\mathrm{a}}\left(\frac{p^{\prime}}{P_{\mathrm{a}}}\right)^{N}
$$




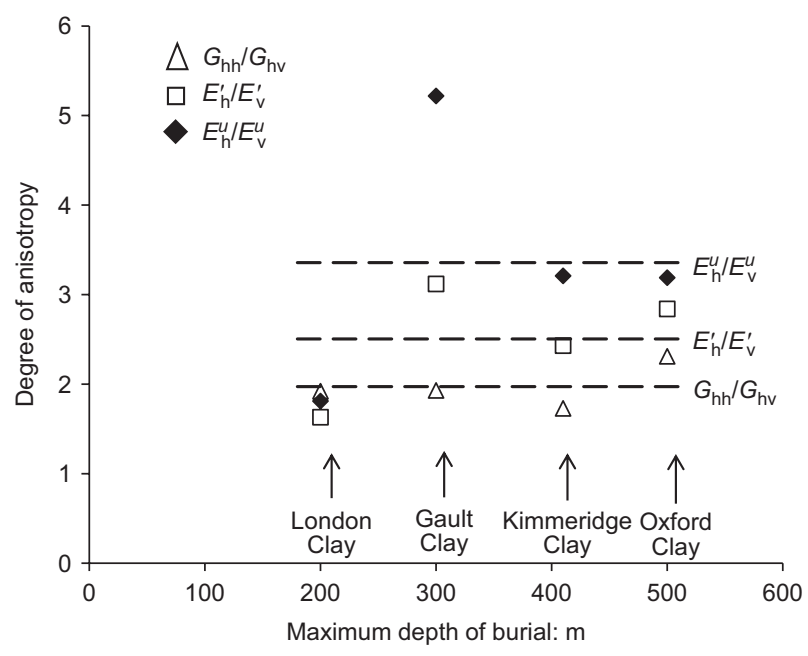

Fig. 6. Degrees of elastic shear stiffness anisotropy on natural Gault, Kimmeridge, Oxford clays and (after Gasparre et al., 2007b) London Clay, related to maximum burial depth

In common with Lings et al. (2000) and the London Clay study by Gasparre et al. (2007b) the void ratio normalising function $f(e)=e^{-1 \cdot 3}$ proposed by Jamiolkowski et al. (1991, 1995) was adopted, although the alternative void ratio normalisation proposed by Rampello \& Viggiani (2001) is discussed later. Note that in equation (8), $P_{\mathrm{a}}$ is the atmospheric pressure (nominally $100 \mathrm{kPa}$ ). The material coefficient $M$ is independent of the system of units applied. The more limited depth ranges of the Gault, Kimmeridge and Oxford clay profiles make it harder to evaluate equivalent relationships between the in situ stiffnesses and effective stresses than was the case for the deeper London Clay profile. The geophysical data tend to scatter due to occasional hard inclusions and also show near-surface fluctuations due to weathering, seasonal variations and other factors.

However, the undrained triaxial, bender element and resonant column tests allow the relationships between elastic stiffness and $p^{\prime}$ to be investigated over ranges above and below in situ $p_{0}^{\prime}$. Comparable trends are also available from tests conducted on normally consolidated reconstituted samples and Figs 7-9 present summary plots for the dynamic $G_{\mathrm{hh}}, G_{\mathrm{hv}}$ and $G_{\theta z}$ values found for Gault, Kimmeridge and Oxford clays. Jamiolkowski et al.'s (1991) void ratio function has been applied and power law functions fitted (equation (8)), which were evaluated to give the 'in situ' $G_{\mathrm{hh}}$, $G_{\text {hv }}$ parameters listed in Table 4 . Key points to note from these plots include the following.

- All four clays' natural samples show markedly higher bender element $G_{\mathrm{hh}}$ than $G_{\mathrm{vh}}$ (or $G_{\mathrm{hv}}$ ) values at all $p^{\prime}$ levels, maintaining practically constant ratios of $1 \cdot 5$ to $2 \cdot 5$.

- The power law exponents $N$ applying to the natural clays' shear stiffnesses (after normalisation by $f(e)$ ) are well below unity, ranging from 0.47 to 0.50 for Gault and Oxford clays and falling between $0 \cdot 21$ and $0 \cdot 37$ for the Kimmeridge. Similar trends apply to London Clay; Gasparre et al. (2007a, 2007b).

- The resonant column HCA $G_{\theta z}$ and triaxial bender element $G_{\mathrm{hv}}$ tests, which involve the same shearing mode, give broadly comparable if not identical, trends. With Gault Clay $G_{\mathrm{hh}}>G_{\theta z}>G_{\mathrm{hv}}$ while $G_{\theta z}<G_{\mathrm{hv}}$ for Kimmeridge Clay and $G_{\theta z} \approx G_{\mathrm{hv}}$ in the Oxford Clay case. These discrepancies may reflect the tests' different

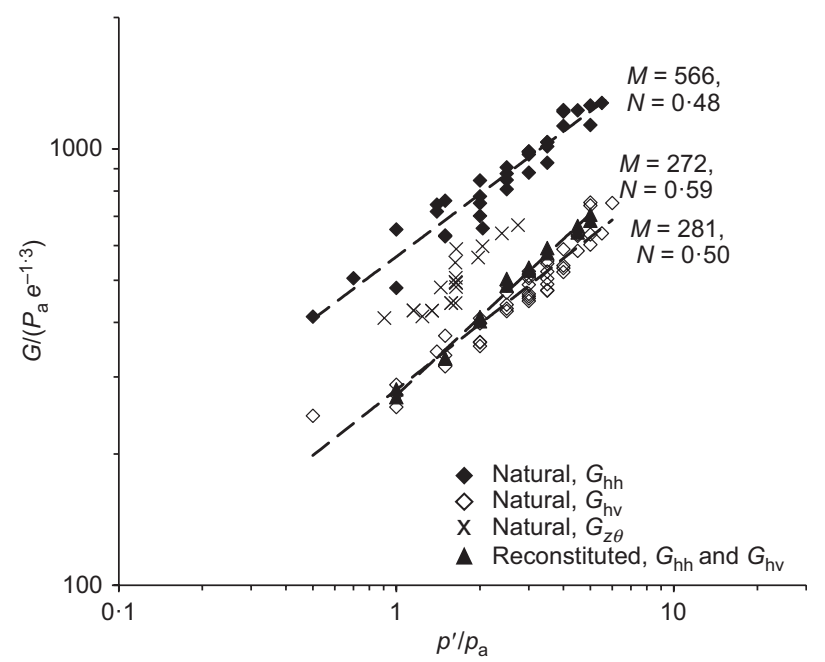

Fig. 7. Elastic shear stiffness $G_{\mathrm{hh}}$ and $G_{\mathrm{hv}}$ measurements made by bender element tests on natural and reconstituted Gault Clay, along with $\mathrm{HCA}$ resonant column $G_{\theta z}$ trends; normalised for void ratio

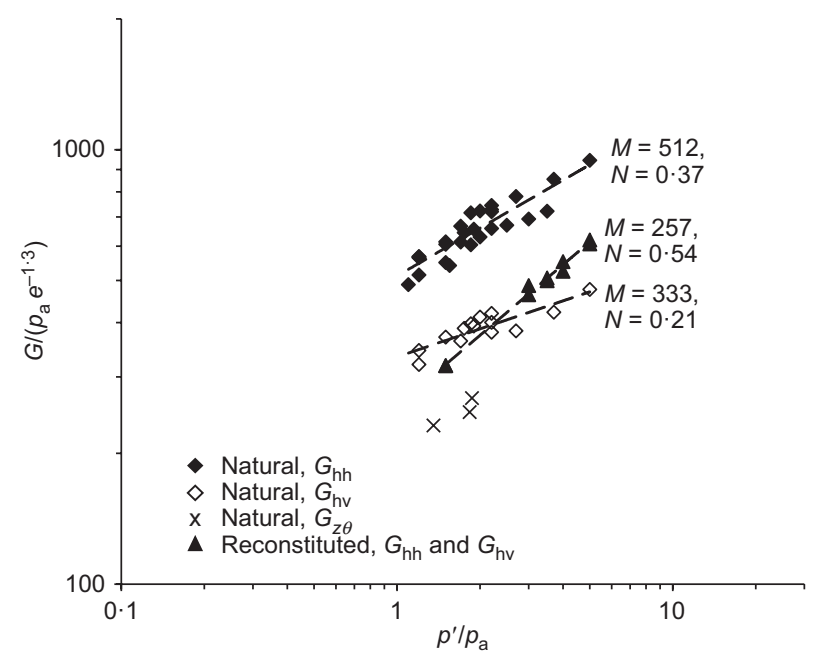

Fig. 8. Elastic shear stiffness $G_{\mathrm{hh}}$ and $G_{\mathrm{hv}}$ measurements made by bender element tests on natural and reconstituted Kimmeridge Clay, along with $\mathrm{HCA}$ resonant column $G_{\theta z}$ trends; normalised for void ratio

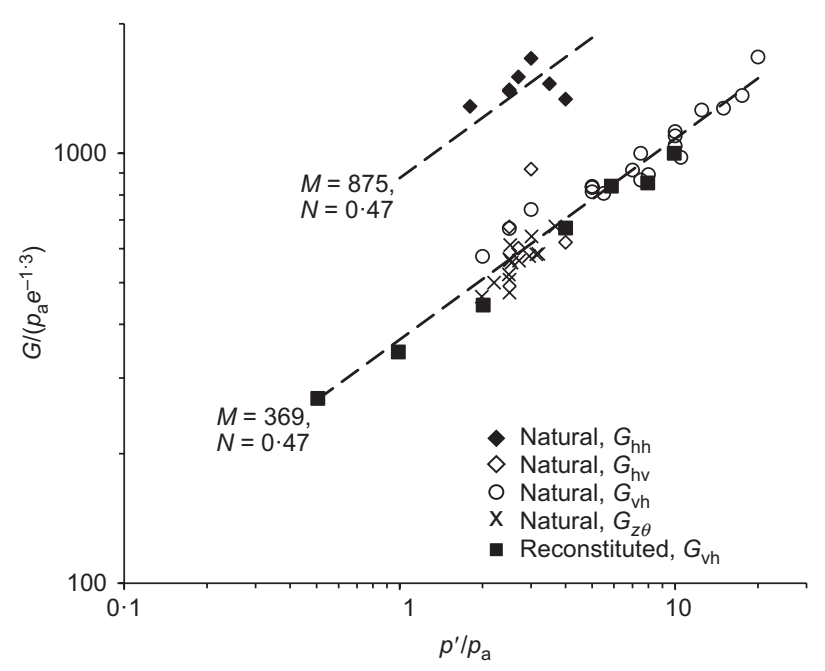

Fig. 9. Elastic shear stiffness $G_{\mathrm{hh}}$ and $G_{\mathrm{hv}}$ measurements made by bender element tests on natural and reconstituted Oxford Clay, along with $\mathrm{HCA}$ resonant column $G_{\theta z}$ trends; normalised for void ratio 
physical principles, specimen geometries and strain rates. It is also possible that the elastic models applied in the interpretation are not fully applicable to bedded and fissured natural stiff clays composed of potentially highly oriented particles.

- The isotropically consolidated reconstituted samples showed little or no difference between $G_{\mathrm{hh}}$ and $G_{\mathrm{vh}}$ bender element trends.

- Although scattered, the $G_{\mathrm{vh}}$ moduli from in situ shear wave tests are broadly compatible with the laboratory trends, exceeding the bender element values for the Gault and London clays, but falling below those for the Oxford Clay and overlapping that for the Kimmeridge. The resonant column data fall closer to the field trends, except for the Gault Clay. However, the field cross-hole $G_{\mathrm{hh}}$ ranges tend to exceed the laboratory bender element values more significantly, possibly due to the presence of hard bands that provide 'short cuts' for horizontally travelling waves in the field, leading to possibly unrepresentative overall indications of anisotropy. As shown later, better agreement is seen with $G_{\mathrm{hh}}$ data from the HCA tests.

\section{Influence of structure on elastic stiffness}

After normalisation for void ratio, the vertical platen-to-platen $G_{\mathrm{vh}}$ measurements made on reconstituted samples vary only slightly from the natural samples' $G_{\mathrm{hv}}$ bender element trends in Figs 7-9, indicating that microstructure does not influence this elastic stiffness component strongly.

A comparison of all of the $G_{\mathrm{vh}}$ and $G_{\mathrm{hv}}$ bender element data is given in Fig. 10(a). Since complementary tests on intact and reconstituted samples were not available for London Clay unit B2c, measurements from the slightly deeper sub-unit B2a are shown. The tests on reconstituted soils show a surprisingly narrow band, with only the London Clay plotting slightly higher than the means. The intact samples indicate slightly more variability, as a result of small but varied effects of structure. For both the London Clay and the Gault Clay there are apparently 'negative' effects of structure, with the intact samples displaying lower normalised stiffnesses than the reconstituted. For the Oxford Clay the effect of structure is 'positive' at lower effective stress levels but reduces as the stress increases, because of a slightly lower exponent $N$ for the intact soil, while the distinctly lower $N$ value of the intact Kimmeridge Clay implies an influence of structure that changes from 'positive' to 'negative' as $p^{\prime}$ increases. Age and depth of burial therefore appear to have no clear effect on either the degree of anisotropy of the clays or the overall magnitude of the stiffness as quantified by the elastic stiffness in the vertical plane.

The above interpretive approach assumes implicitly that the adopted $f(e)$ function accounts for differences in state between normally consolidated reconstituted and overconsolidated intact samples. Fig. 10(b) explores the impact of applying the alternative normalisation approach proposed by Rampello \& Viggiani (2001). The state is quantified using an equivalent pressure on the intrinsic isotropic normal compression line, $p_{\mathrm{e}}^{\prime}=\exp [(N-v) / \lambda]$, where $\lambda$ and $N$ are the values of the gradient and intercept at $1 \mathrm{kPa}$ of the intrinsic isotropic compression lines in the $v: \ln p^{\prime}$ plane adopting the values reported by Hosseini Kamal et al. (2014). The stiffnesses are then normalised by the equivalent stiffness of the normally consolidated soil at the current void ratio or specific volume. Jovičić \& Coop (1997) employed a similar approach to interpret tests on sands, although they normalised with respect to the stiffness of the normally consolidated soil at the same $p^{\prime}$ rather than the same void ratio.

Rampello and Viggiani's approach leads to all normally consolidated reconstituted samples plotting at $G_{0} /\left[A\left(p_{\mathrm{e}}^{\prime}\right)^{n}\right]=1=p^{\prime} / p_{\mathrm{e}}^{\prime}$, while the intact (overconsolidated) specimen tests span the $0.1<p^{\prime} / p_{\mathrm{e}}^{\prime}<0.6$ range. Despite this lack of overlap, the normalised stiffness ratios of the intact London and Kimmeridge Clay tests trend towards $G_{0} /\left(A\left(p_{\mathrm{e}}^{\prime}\right)^{n}\right)$ values at $p^{\prime} / p_{\mathrm{e}}^{\prime}=1$ that plot well below the single reconstituted point, indicate a value close to unity for Gault Clay and only plot marginally above unity for the Oxford Clay. While further tests on overconsolidated reconstituted specimens could confirm the relative correspondence at lower $p^{\prime} / p_{\mathrm{e}}^{\prime}$ more precisely, the available data support the conclusion reached by Gasparre et al. (2007a) with London Clay that an intact structure does not enhance the stiff clays' normalised bender element stiffnesses.

The effects of structure on small-strain stiffness do not appear to correlate systematically with those identified for

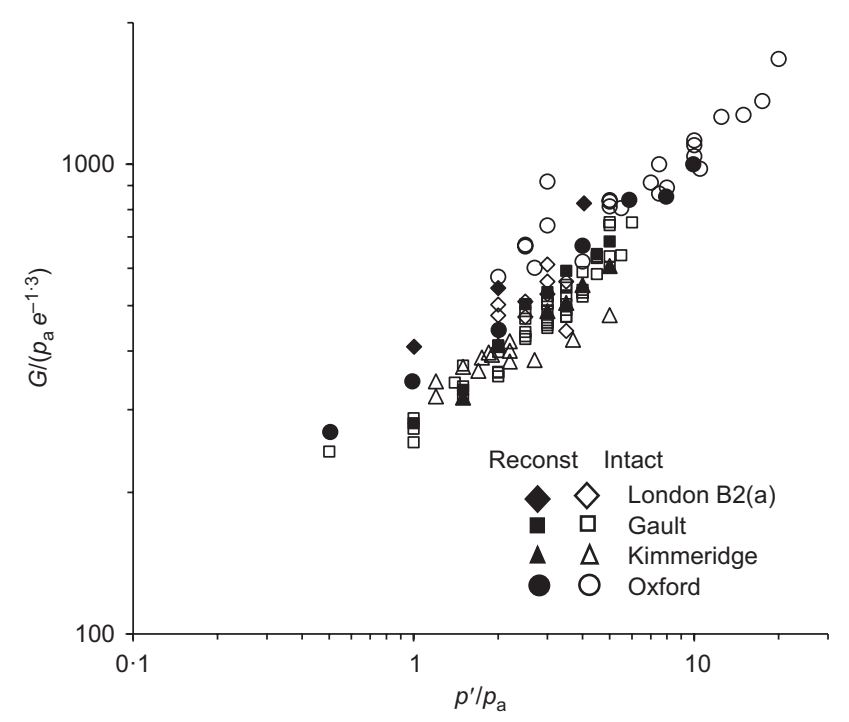

(a)

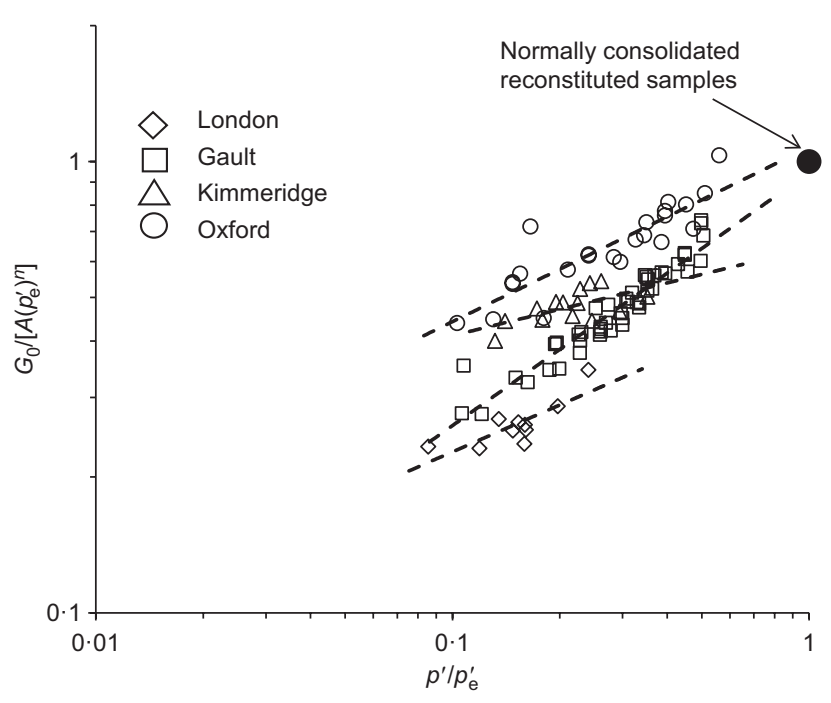

(b)

Fig. 10. Comparison of bender element $G_{\mathrm{vh}}$ and $G_{\mathrm{hv}}$ data for the intact and reconstituted clays: (a) using a void ratio function; (b) following framework of Rampello \& Viggiani (2001) 
shear strength and compressibility by Hosseini Kamal et al. (2014). The microstructure of unfissured Oxford Clay imparted a large positive effect on its shear strength. The London Clay's microstructure also led to a less marked, but still positive, effect on the shear strength of specimens that did not fail on pre-existing (meso-fabric) fissures. Both the Gault and Kimmeridge clays indicated negative overall effects of structure on strength, due to their more intensely fissured meso-fabrics. However, the potential influence of meso-structure on stiffness is not clear, as Gasparre et al. (2007a) found no systematic difference in the stiffness of samples that did, or did not, fail on pre-existing fissures. Natural structure had the greatest influence on the onedimensional compressive behaviour of the London Clay, followed by the Kimmeridge and Oxford clays, with the Gault Clay displaying the least. It appears that the interacting effects of micro- and meso-structure lead to diverse degrees of impact when considering different stress paths and strain levels.

\section{Undrained triaxial compression stiffness characteristics} over the non-linear range

The non-linear stiffness response was investigated in multiple undrained triaxial and HCA tests taken to failure. Figs 11-13 show how the vertical undrained secant stiffness $E_{\mathrm{v}}^{\mathrm{u}}$ varied with axial strain (where $\varepsilon_{\mathrm{a}}=\varepsilon_{\mathrm{s}}$ under undrained conditions) in triaxial compression tests conducted from a range of isotropic stress states. Each curve degrades from an initial linear plateau that extends to less than $0.002 \%$ strain in most cases, although some tests clearly manifest more scatter than others.

One reassuring feature seen in Fig. 11 is that the rotary cored samples taken at shallow depth in Gault Clay show very similar trends at equivalent $p^{\prime}$ levels to tests on block sample specimens, indicating that the Geobor-S rotary coring did not damage the clays' stiffness characteristics. The undrained stiffness data are explored further in Figs $14-16$ by plotting the secant values at $\varepsilon_{\mathrm{a}}$ levels of $0.001,0.01,0.1$ and $1 \%$, from the initial $Y_{1}$ response up

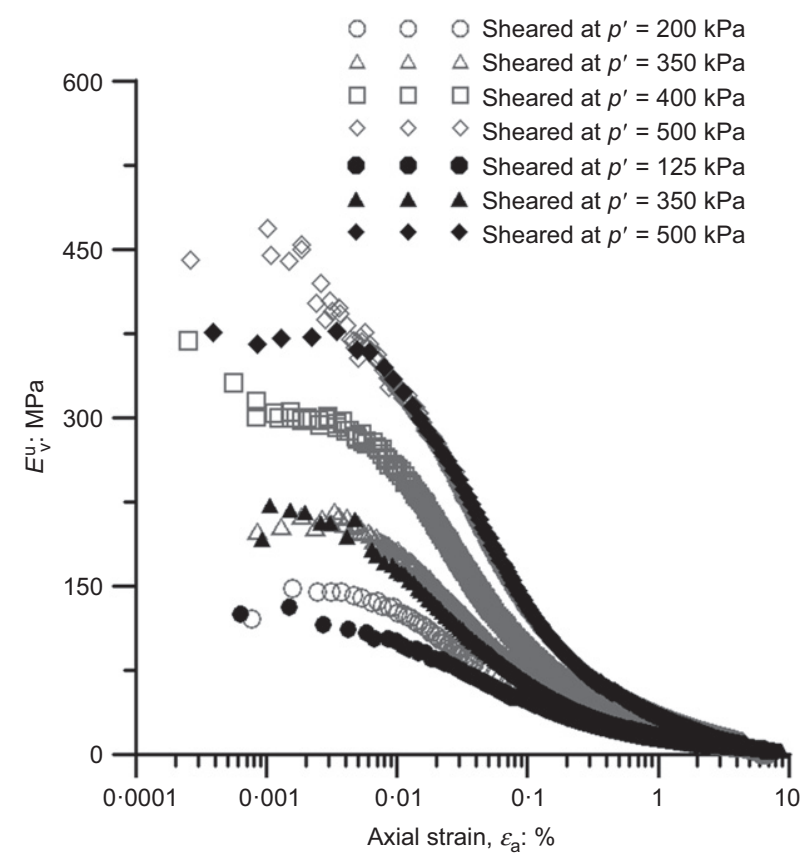

Fig. 11. Non-linear stiffness-strain relationships from undrained triaxial experiments on Gault Clay; open symbols report tests on block samples, closed symbols from rotary core samples to near failure conditions. Relationships are fitted with the form of equation (8), but without $f(e)$ normalisation. It is interesting that higher effective stress level exponents applied to the very small strain $E_{\mathrm{v}}^{\mathrm{u}}$ values than the bender element and resonant column shear stiffnesses, particularly for the Gault and Kimmeridge clays. The exponents decline with increasing strain level, as noted in more recent experiments on natural London Clay (Gasparre et al., 2014) but following the opposite trend to what is commonly assumed within a critical state type of approach, where the exponent is assumed to increase towards unity at large strains (e.g. Viggiani \& Atkinson, 1995; Jovičić \& Coop, 1997). Allowing for the differences of void ratio, indicates again that age or depth of burial do not impact clearly on the stiffness trends. The Kimmeridge Clay has a much lower void ratio,

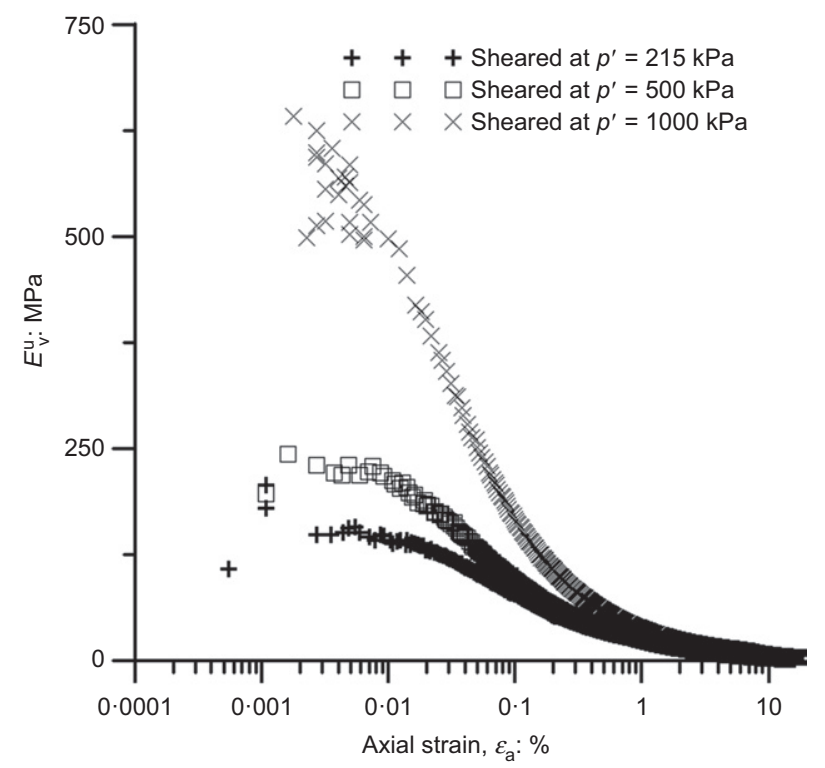

Fig. 12. Non-linear stiffness-strain relationships from undrained triaxial experiments on Kimmeridge Clay; all tests on rotary core samples

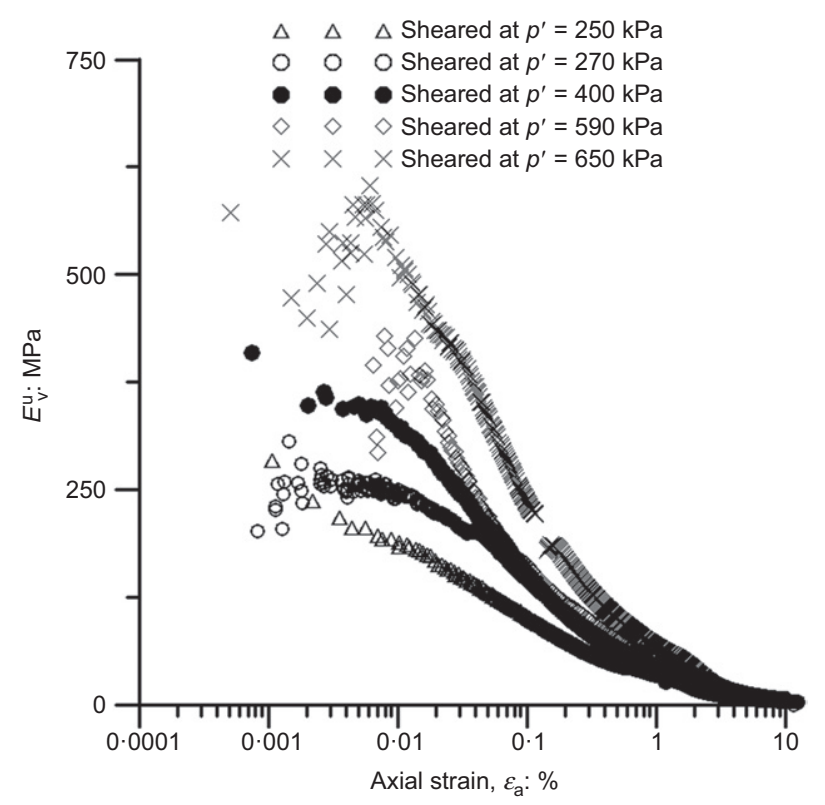

Fig. 13. Non-linear stiffness-strain relationships from undrained triaxial experiments on Oxford Clay; all tests on block samples 


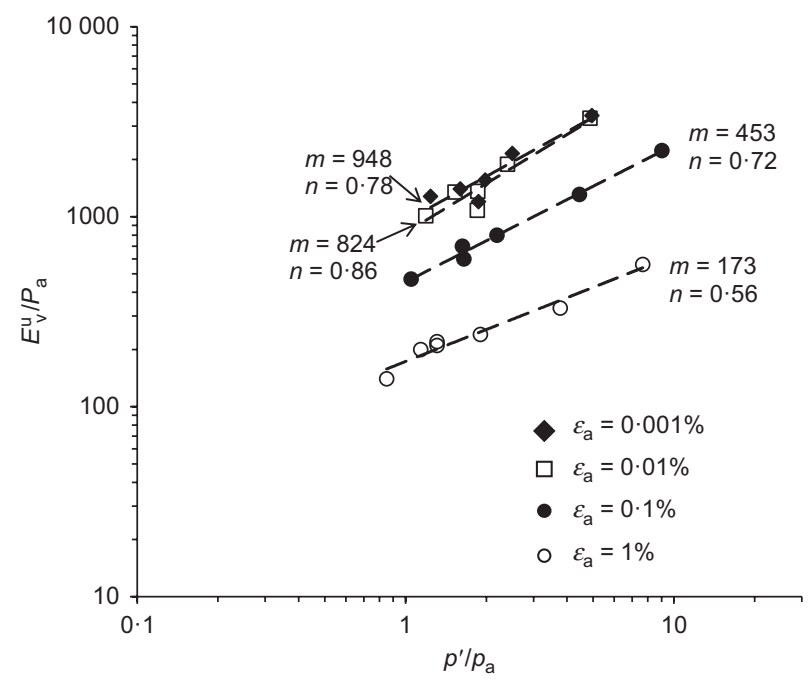

Fig. 14. Relationships between secant undrained triaxial compression stiffness and mean effective stress at four strain levels: Gault Clay

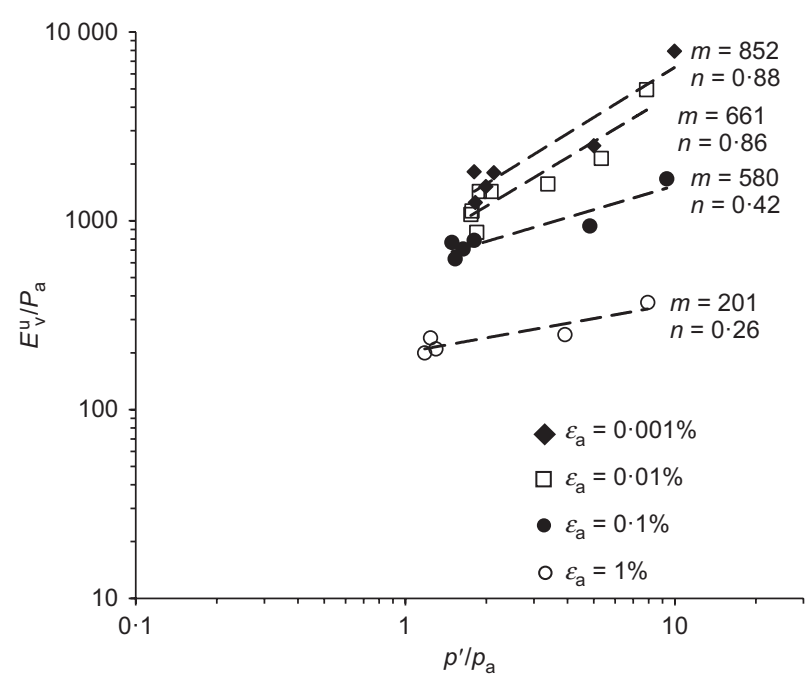

Fig. 15. Relationships between secant undrained triaxial compression stiffness and mean effective stress at four strain levels: Kimmeridge Clay



Fig. 16. Relationships between secant undrained triaxial compression stiffness and mean effective stress at four strain levels: Oxford Clay greater age and depth of burial, yet its stiffnesses are broadly similar to those of the Gault Clay. The different logarithmic Young's modulus-pressure trend gradients and intercepts shown in Figs 14-16 hamper comparisons, but if the 0.001\% strain level and mid-range $p^{\prime} / p_{\mathrm{a}}^{\prime}=3$ condition is considered, then $E_{\mathrm{v}}^{\mathrm{u}} / p_{\mathrm{a}}^{\prime}=2233$ is obtained for the Gault Clay, 2240 for the Kimmeridge Clay and a significantly higher 3020 for the oldest and most deeply buried Oxford Clay.

Undrained stiffness anisotropy over the full non-linear range

Triaxial tests are limited to exploring how $E_{\mathrm{v}}^{\mathrm{u}}$ or $E_{\mathrm{v}}^{\prime}$ vary with strain beyond the elastic $Y_{1}$ limits. Undrained triaxial compression and extension tests on identical specimens should manifest the same initial (vertical) elastic stiffnesses. However, such tests often show different $Y_{1}$ strain limits and subsequent non-linear responses.

An HCA apparatus is required to investigate how other components vary outside the elastic region; Zdravkovic \& Jardine (1997), Anh-Minh (2006) or Nishimura et al. (2007). HCA experiments were conducted to track changes in vertical $E_{\mathrm{v}}^{\mathrm{u}}$, horizontal $E_{\mathrm{h}}^{\mathrm{u}}$ and $G_{\mathrm{vh}}$ in tests on all four clays. The experiments described by Brosse (2012) started from the estimated in situ $p^{\prime}$ and $K_{0}=1.75 \pm 0.05$ conditions and proceeded to failures with $\alpha_{\mathrm{f}}$ values of $0,22 \cdot 5,45,67$ and $90^{\circ}$ while maintaining $b=0 \cdot 5$; she also undertook simple shear HCA tests.

Figures 17-20 present summary plots of the non-linear anisotropy manifested by the four clays. In these plots the vertical and horizontal stiffnesses are both plotted against axial strain, whereas the $G_{\mathrm{vh}}$ traces are plotted against torsional shear strain. Under undrained conditions the vertical strain must equal the sum of the circumferential and radial strains and under near plane strain conditions the latter should be relatively small. The figures also show the initial secant values of $E_{\mathrm{v}}^{\mathrm{u}}, E_{\mathrm{h}}^{\mathrm{u}}$ and $G_{\mathrm{hv}}$ found by fitting linear regression to the test data recorded at strains of up to $0.005 \%$ in the HCA experiments. Brosse (2012) gives further discussion on the particular strain variables chosen for plotting and why the $\alpha_{\mathrm{f}}=67^{\circ}$ tests are less representative and hence are not included here. The limited strain resolution available with the HCA equipment could lead to the 'initial HCA stiffnesses' being smaller than the elastic maxima that might apply at smaller strains.

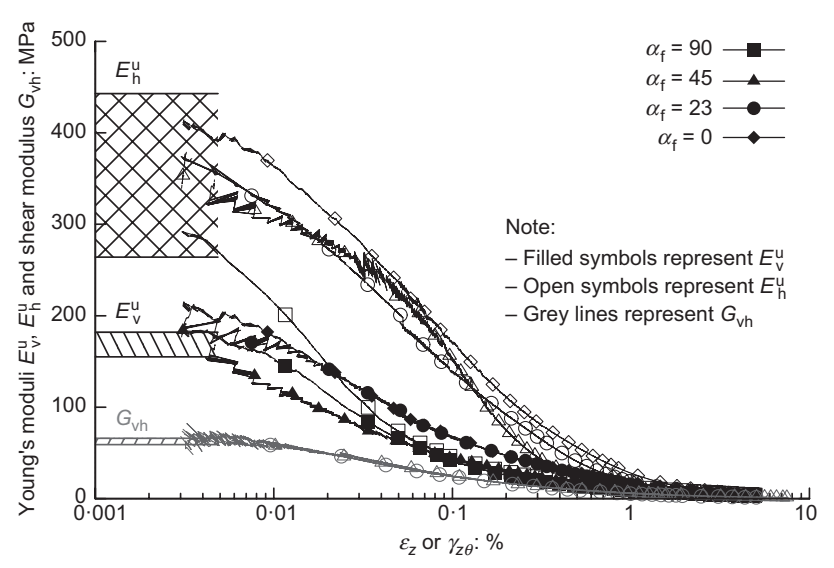

Fig. 17. Secant $E_{\mathrm{v}}^{\mathrm{U}}, E_{\mathrm{h}}^{\mathrm{U}}$ and $G_{\mathrm{vh}}$ degradation curves from HCA stress path tests at five final orientations $\alpha_{\mathrm{f}}$ of the major principal stress axis: Gault Clay. Note triaxial compression elastic $E_{\mathrm{v}}^{\mathrm{u}}=132 \mathrm{MPa}$ and $E_{\mathrm{h}}^{\mathrm{u}}$ from equation (7) $=690 \mathrm{MPa}$. Note also triaxial bender element $G_{v h}=57 \mathrm{MPa}$ and resonant column $70<G_{\mathrm{vh}}<80 \mathrm{MPa}$, while field seismic $80<G_{\mathrm{vh}}<110 \mathrm{MPa}$ (shaded areas give ranges of initial secant moduli from HCA tests) 


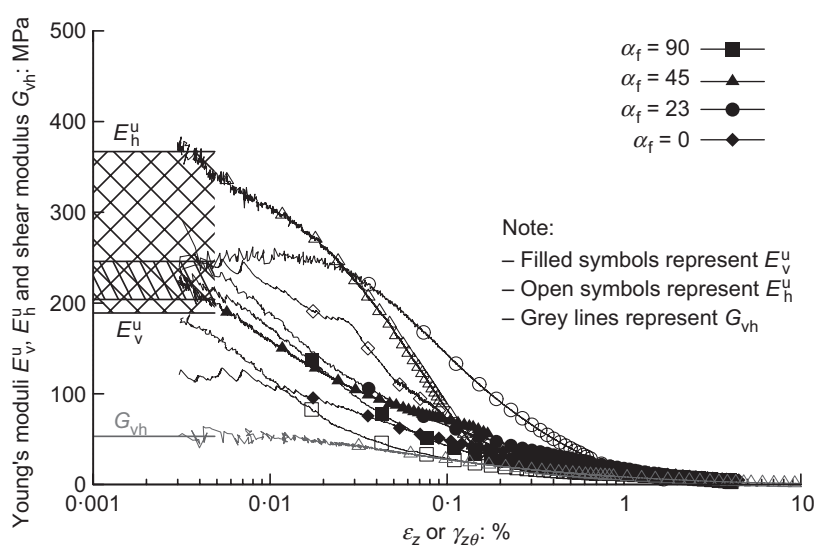

Fig. 18. Secant $E_{\mathrm{v}}^{\mathrm{U}}, E_{\mathrm{h}}^{\mathrm{U}}$ and $G_{\mathrm{vh}}$ degradation curves from HCA stress path tests at five final orientations $\alpha_{\mathrm{f}}$ of the major principal stress axis: Kimmeridge Clay. Note triaxial compression elastic $E_{\mathrm{v}}^{\mathrm{u}}=147 \mathrm{MPa}$ and $E_{\mathrm{h}}^{\mathrm{u}}$ from equation (7) $=472 \mathrm{MPa}$. Note also triaxial bender element $G_{\mathrm{vh}}=70 \mathrm{MPa}$ and resonant column $G_{\mathrm{vh}} \approx 100 \mathrm{MPa}$ while field seismic $50<G_{\mathrm{vh}}<80 \mathrm{MPa}$ (shaded areas give ranges of initial secant moduli from HCA tests)

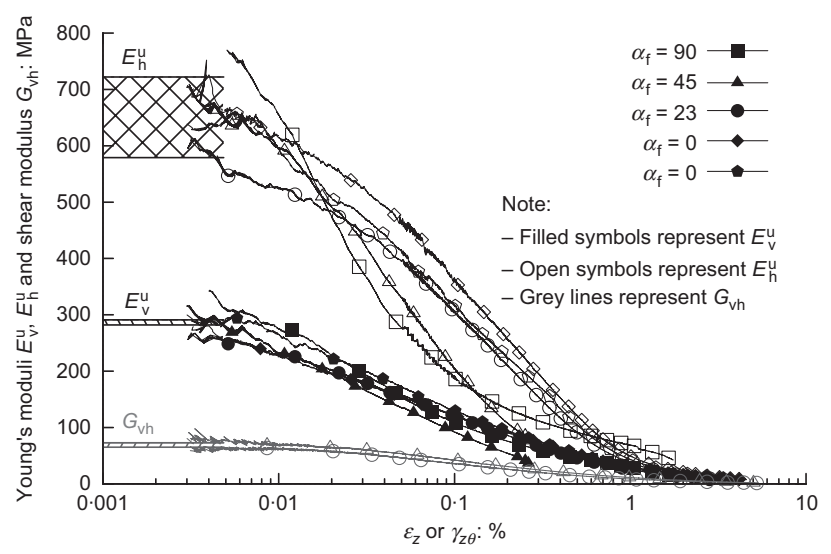

Fig. 19. Secant $E_{\mathrm{v}}^{\mathrm{U}}, E_{\mathrm{h}}^{\mathrm{U}}$ and $G_{\mathrm{vh}}$ degradation curves from HCA stress path tests at five final orientations $\alpha_{\mathrm{f}}$ of the major principal stress axis: Oxford Clay. Note elastic triaxial compression $E_{\mathrm{v}}^{\mathrm{u}}=270 \mathrm{MPa}$ and $E_{\mathrm{h}}^{\mathrm{u}}$ from equation $(7)=862 \mathrm{MPa}$. Note also triaxial bender element $G_{\mathrm{vh}}=105 \mathrm{MPa}$ and resonant column $80<G_{\mathrm{vh}}<95 \mathrm{MPa}$ while field seismic $40<G_{\mathrm{vh}}<70 \mathrm{MPa}$ (shaded areas give ranges of initial secant moduli from HCA tests)

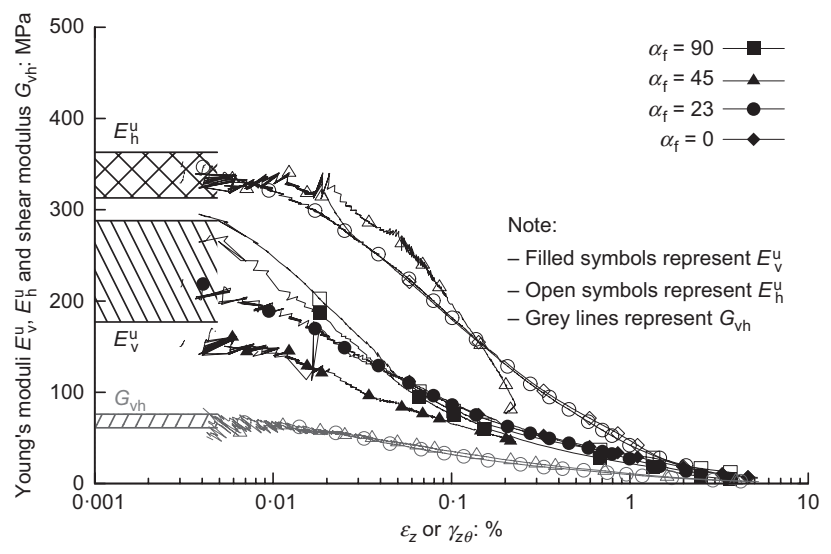

Fig. 20. Secant $E_{\mathrm{v}}^{\mathrm{U}}, E_{\mathrm{h}}^{\mathrm{U}}$ and $G_{\mathrm{vh}}$ degradation curves from HCA stress path tests at five final orientations $\alpha_{\mathrm{f}}$ of the major principal stress axis: London Clay. Note elastic triaxial compression $E_{\mathrm{v}}^{\mathrm{u}}=182 \mathrm{MPa}$ and $E_{\mathrm{h}}^{\mathrm{u}}$ from equation $(7)=330 \mathrm{MPa}$. Note also triaxial bender element $G_{\mathrm{vh}}=60 \mathrm{MPa}$ and resonant column $80<G_{\mathrm{vh}}<90 \mathrm{MPa}$ while field seismic $75<G_{\mathrm{vh}}<105 \mathrm{MPa}$ (shaded areas give ranges of initial secant moduli from HCA tests).
The experiments highlight some of the limitations of the cross-anisotropic elastic framework to the interpretation of complex soil behaviour. The stiffness parameters of any truly elastic system should be stress path independent. While the $G_{\mathrm{vh}}$ traces for any given clay fall within a relatively tight spread, the $E_{\mathrm{h}}^{\mathrm{u}}$ traces vary significantly with the HCA stress path followed. The $E_{\mathrm{v}}^{\mathrm{u}}$ characteristics show intermediate trends. Other key points are given below.

- Despite the HCA tests' limited strain resolution and the problems of applying elastic theory, the initial HCA secant stiffnesses are broadly compatible with the elastic stiffnesses determined at smaller strains in triaxial, bender element and resonant column tests that are listed in Table 4 and shown in the figure captions.

- The maximum HCA $E_{\mathrm{v}}^{\mathrm{u}}$ values fall close to the triaxial measurements for all cases except the Kimmeridge Clay, where their average is considerably higher.

- The equivalent HCA $G_{\mathrm{vh}}$ maxima generally match the bender element data for all cases apart from the Oxford Clay, but fall below the resonant column range for all four strata. Brosse (2012) also shows how $G_{\mathrm{hh}}$ data can be obtained from the HCA tests, giving values that tend to exceed the bender element outcomes but match better the cross-hole field measurements.

- However, the initial maxima HCA $E_{\mathrm{h}}^{\mathrm{u}}$ fall well below the values computed by substituting triaxial and bender element data into equation (7) for all cases except the London Clay. Given the above described difficulties of applying the equation (7) approach reliably, the present authors conclude that the HCA data are more representative, even at very small strains.

- The HCA traces show continuous reductions in secant stiffness with increasing strain from their initial maxima. All four clays manifest clear anisotropy over their full non-linear ranges with $G_{\mathrm{vh}}<E_{\mathrm{v}}^{\mathrm{u}}<E_{\mathrm{h}}^{\mathrm{u}}$.

As described by Zdravkovic \& Jardine (1997), Anh-Minh (2006) and Nishimura et al. (2007), drained incrementally uniaxial' HCA tests can also provide direct measurements of all the effective stress cross-anisotropic stiffness parameters over the full range of strain.

Detailed information on non-linear undrained stiffness anisotropy has not been available previously for the strata considered, which cover wide areas in the south east of the UK. The new findings will allow improved modelling involving such stiff clays, addressing the practical engineering problems raised, for example, by Addenbrooke et al. (1997).

\section{SUMMARY AND CONCLUSIONS}

A large proportion of the southern UK is underlain by stiff, high-plasticity clays. Improving their geotechnical characterisation is central to efficient geotechnical engineering in multiple major infrastructure projects. An integrated study has been made of the stiffness behaviour of the Gault, Kimmeridge, Oxford and London clays. High-quality rotary and block samples were tested in advanced triaxial and hollow cylinder stress path experiments, involving local strain, multi-axial bender element and resonant column techniques. The overall findings are listed below.

(a) Field, triaxial and HCA experiments offer overlapping capabilities. Their outputs can be integrated to develop comprehensive descriptions of stiffness in soils that are markedly anisotropic, pressure dependent and highly non-linear. 
(b) The laboratory experiments led to a spread of resonant column, bender element and static HCA measurements that were broadly compatible with 'field' $G_{\mathrm{vh}}$ ranges, which were themselves subject to significant scatter. However, the bender element $G_{\mathrm{hh}}$ values fell significantly below cross-hole field measurements, possibly due to the influence of hard bands in the field. However, $G_{\mathrm{hh}}$ values from HCA tests matched the field trends better.

(c) The direct drained and undrained measurements of elastic $E_{\mathrm{v}}^{\prime}, E_{\mathrm{v}}^{\mathrm{u}}, v_{\mathrm{vh}}^{\prime}, G_{\mathrm{vh}}$ and $G_{\mathrm{hh}}$ values interpreted from bender element equipped triaxial experiments are more reliable than the estimates for $E_{\mathrm{h}}^{\mathrm{u}}, v_{\mathrm{hh}}^{\prime}$ and $v_{\mathrm{hv}}^{\prime}$ that can be derived by following less direct expressions derived from elastic theory. Values of $E_{\mathrm{h}}^{\prime}$ derived from the triaxial tests have an intermediate reliability.

(d) While undrained triaxial tests can show how $E_{\mathrm{v}}^{\mathrm{u}}$ decays with strain, only undrained HCA tests can show how $E_{\mathrm{h}}^{\mathrm{u}}$ and $G_{\mathrm{vh}}$ vary over the non-linear range. They can also provide representative measurements of the initial $E_{\mathrm{v}}^{\mathrm{u}}$, $E_{\mathrm{h}}^{\mathrm{u}}$ and $G_{\mathrm{vh}}$ moduli.

(e) The experiments identified no clear effect of age or maximum burial depth on the stiffness anisotropy, the extents of the linear $Y_{1}$ ranges or on the overall magnitude of elastic stiffness. After normalising for void ratio, the range of $G_{\mathrm{vh}}$ or $G_{\mathrm{hv}}$ values was remarkably similar between the different clays for both intact and reconstituted samples.

$(f)$ Detailed information on non-linear undrained stiffness anisotropy was obtained that has not been available previously for such strata. The new findings will be of great value in improving the modelling of practical problems involving undrained shearing in such stiff clays across wide areas of the UK and in other countries.

\section{APPENDIX 1}

For a cross-anisotropic material, under the triaxial apparatus conditions, equation (1) reduces to

$$
\left\{\begin{array}{c}
\delta \epsilon_{\mathrm{v}} \\
\delta \epsilon_{\mathrm{h}}
\end{array}\right\}=\left[\begin{array}{cc}
\frac{1}{E_{\mathrm{v}}^{\prime}} & -\frac{2 v_{\mathrm{hv}}^{\prime}}{E_{\mathrm{h}}^{\prime}} \\
-\frac{v_{\mathrm{vh}}^{\prime}}{E_{\mathrm{v}}^{\prime}} & \frac{1-v_{\mathrm{hh}}^{\prime}}{E_{\mathrm{h}}^{\prime}}
\end{array}\right]\left\{\begin{array}{l}
\delta \sigma_{\mathrm{v}}^{\prime} \\
\delta \sigma_{\mathrm{h}}^{\prime}
\end{array}\right\}
$$

For an elastic material (within $Y_{1}$ ) the matrix is symmetric and

$$
\frac{v_{\mathrm{vh}}^{\prime}}{E_{\mathrm{v}}^{\prime}}=\frac{v_{\mathrm{hv}}^{\prime}}{E_{\mathrm{h}}^{\prime}}
$$

In drained horizontal loading where $\Delta \sigma_{\mathrm{v}}^{\prime}=0$ the following equation was obtained

$$
\begin{aligned}
& \delta \epsilon_{\mathrm{v}}=-\frac{2 v_{\mathrm{hv}}^{\prime}}{E_{\mathrm{h}}^{\prime}} \delta \sigma_{\mathrm{h}}^{\prime} \\
& \delta \epsilon_{\mathrm{h}}=-\frac{1-v_{\mathrm{hh}}^{\prime}}{E_{\mathrm{h}}^{\prime}} \delta \sigma_{\mathrm{h}}^{\prime}
\end{aligned}
$$

For a cross-anisotropic material, there is the following equation

$$
G_{\mathrm{hh}}=\frac{E_{\mathrm{h}}^{\prime}}{2\left(1+v_{\mathrm{hh}}^{\prime}\right)}
$$

By combining equations (11)-(13), the equation below is obtained

$$
E_{\mathrm{h}}^{\prime}=\frac{4 A G_{\mathrm{hh}}}{A+2 G_{\mathrm{hh}}}
$$

$$
v_{\mathrm{hh}}^{\prime}=\frac{A-2 G_{\mathrm{hh}}}{A+2 G_{\mathrm{hh}}}
$$

where $A=\delta \sigma_{\mathrm{h}}^{\prime} / \delta \epsilon_{\mathrm{h}}$.

\section{APPENDIX 2}

A hollow cylinder is able to control four independent stress variables and measure the four related strains. Therefore, up to four sets of stress-strain relationships can be measured independently in general HCA tests. It is therefore not possible to resolve the five independent drained parameters required to describe a crossanisotropic material from such measurements unless specific stress paths are followed. However, in the undrained case, the soil deforms at constant volume and the additional relationships given in equations (16) and (17) below apply (Gibson, 1974)

$$
\begin{aligned}
& v_{\mathrm{vh}}^{\mathrm{U}}=\frac{1}{2} \\
& v_{\mathrm{hh}}^{\mathrm{U}}=1-v_{\mathrm{hv}}^{\mathrm{U}}=1-\frac{1}{2} \frac{E_{\mathrm{h}}^{\mathrm{U}}}{E_{\mathrm{v}}^{\mathrm{U}}}
\end{aligned}
$$

Therefore, in the undrained case, a cross-anisotropic material can be described by three independent parameters only, chosen here as $E_{\mathrm{v}}^{\mathrm{U}}, E_{\mathrm{h}}^{\mathrm{U}}$ and $G_{\mathrm{vh}}$. Consequently, these can be resolved from the four pairs of stresses and strains measured in a HCA. By combining equations (1), (16) and (17), the following relationships are obtained

$$
\begin{aligned}
& E_{\mathrm{v}}^{\mathrm{U}}=\frac{2 \delta \sigma_{z}-\delta \sigma_{\mathrm{r}}-\delta \sigma_{\theta}}{2 \delta \varepsilon_{z}} \\
& E_{\mathrm{hr}}^{\mathrm{U}}=\frac{\delta \sigma_{\mathrm{r}}\left(\delta \sigma_{\mathrm{r}}-2 \delta \sigma_{z}\right)-\delta \sigma_{\theta}\left(\delta \sigma_{\theta}-2 \delta \sigma_{z}\right)}{\delta \varepsilon_{\mathrm{r}}\left(\delta \sigma_{\mathrm{r}}+\delta \sigma_{\theta}-2 \delta \sigma_{z}\right)+\delta \varepsilon_{z}\left(\delta \sigma_{\theta}-\delta \sigma_{z}\right)} \\
& E_{\mathrm{h} \theta}^{\mathrm{U}}=\frac{\delta \sigma_{\mathrm{r}}\left(\delta \sigma_{\mathrm{r}}-2 \delta \sigma_{z}\right)-\delta \sigma_{\theta}\left(\delta \sigma_{\theta}-2 \delta \sigma_{z}\right)}{\delta \varepsilon_{\theta}\left(\delta \sigma_{\mathrm{r}}+\delta \sigma_{\theta}-2 \delta \sigma_{z}\right)+\delta \varepsilon_{z}\left(\delta \sigma_{\mathrm{r}}-\delta \sigma_{z}\right)} \\
& G_{\mathrm{vh}}=\frac{\delta \tau_{z \theta}}{\delta \gamma_{z \theta}}
\end{aligned}
$$

The authors assumed that due to the isotropy in the horizontal plane: $\sigma_{x}\left(\varepsilon_{x}\right)$ is equivalent to $\sigma_{\mathrm{r}}\left(\varepsilon_{\mathrm{r}}\right)$ and $\sigma_{y}\left(\varepsilon_{y}\right)$ is equivalent to $\sigma_{\theta}\left(\varepsilon_{\theta}\right)$.

As the above equations involve multiple stress and strain measurements, scatter is observed, especially in the lower strain range. In order to clarify the trends at lower strains, two actions were taken: least-square linear regressions were carried out over the strain range up $0.005 \%$ in order to determine best-fit initial $E_{\mathrm{v}}^{\mathrm{U}}, E_{\mathrm{h}}^{\mathrm{U}}$ and $G_{\mathrm{vh}}$ values and a Savitzky-Golay filter was applied over the next order of magnitude of strain range (i.e. from $0.005 \%$ to $0.05 \%$ ) to the $\varepsilon_{\mathrm{r}}, \varepsilon_{\theta}, \sigma_{z}, \sigma_{\mathrm{r}}$ and $\sigma_{\theta}$ datasets.

\section{ACKNOWLEDGEMENTS}

The authors acknowledge with thanks the Engineering and Physical Science Research Council's (EPSRC's) funding of the research described under grants EP/E029957/1 and EP/D506387/1 and the recent contributions made at Imperial College by Alan Bolsher, Steven Ackerley, Graham Keefe, Drs Clark Fenton and Stephen Wilkinson, as well as the earlier work of Drs Liana Gasparre, Nguyen Ann-Minh and Satoshi Nishimura on the London Clay. The authors are also grateful to Darren Ward and In Situ Site Investigation for the CPT profiling at the sampling sites, to Professor Malcolm Bolton and Brian Lees for access to the High Cross site at Cambridge, Duncan Nicholson, Stewart Jarvis and Lindsay Barnard from Ove Arup Ltd, for providing access to the Elstow site and Neil Walker who kindly allowed the sampling of Kimmeridge Clay from his land. They would also like to thank Arup Geotechnics for permission to use data from their Site Investigation report for The Wixams, Bedford. 


\section{NOTATION}

$A$ gradient $\mathrm{d} \sigma_{\mathrm{r}} / \mathrm{d} \varepsilon_{\mathrm{r}}$ for a radial probing test

$B$ Skempton's pore pressure parameter

$b$ measure of intermediate principal stress $=\left(\sigma_{2}^{\prime}-\sigma_{3}^{\prime}\right) /\left(\sigma_{1}^{\prime}-\sigma_{3}^{\prime}\right)$

$E_{\mathrm{h}}^{\prime}, E_{\mathrm{v}}^{\prime} \quad$ drained Young's moduli for cross-anisotropic elastic soil

$E_{\mathrm{h}}^{\mathrm{u}}, E_{\mathrm{v}}^{\mathrm{u}} \quad$ undrained Young's moduli for cross-anisotropic elastic soil

$e$ void ratio

$f_{\mathrm{s}}$ sleeve friction

$G_{\mathrm{hh}} \quad$ shear modulus in horizontal plane

$G_{\mathrm{hv}}, G_{\mathrm{vh}}, G_{z \theta}$ shear moduli in vertical plane

$K_{0} \quad$ coefficient of earth pressure at rest

$M$ material coefficient

$m$ intercept of $\log E / p_{\mathrm{a}}: \log p^{\prime} / p_{\mathrm{a}}$ relationship

$N$ intercept at $1 \mathrm{kPa}$ of intrinsic isotropic compression line in $v: \ln p^{\prime}$ plane

$n \quad$ gradient of $\log E / p_{\mathrm{a}}: \log p^{\prime} / p_{\mathrm{a}}$ relationship

$P_{\text {a }} \quad$ atmospheric pressure

$p^{\prime} \quad$ mean effective stress

$p_{0}^{\prime} \quad$ initial mean effective stress

$p_{\mathrm{e}}^{\prime} \quad$ equivalent pressure used in normalisation

$q$ deviatoric stress $=\left(\sigma_{\mathrm{a}}-\sigma_{\mathrm{r}}\right)$ in triaxial tests

$q_{\mathrm{c}}$ cone resistance

$S_{\mathrm{u}} \quad$ undrained strength

$V_{\mathrm{hh}}, V_{\mathrm{hv}}$ velocities of horizontally travelling bender element shear waves with horizontal or vertical polarisation, respectively

$v$ specific volume

$\alpha$ inclination of major principal stress to sample vertical direction

$\alpha_{\mathrm{f}} \quad$ value of $\alpha$ at failure

$\gamma$ bulk unit weight

$\gamma_{z \theta} \quad$ shear strain in vertical plane

$\varepsilon_{\mathrm{a}}$ axial strain, also vertical strain $\varepsilon_{z}$

$\varepsilon_{\mathrm{r}}$ radial strain, also horizontal strain $\varepsilon_{y}$

$\varepsilon_{\theta} \quad$ circumferential strain, also horizontal strain $\varepsilon_{x}$

$\lambda$ gradient of intrinsic isotropic compression line in $v: \ln p^{\prime}$ plane

$v_{\mathrm{hh}}^{\prime}, v_{\mathrm{hv}}^{\prime}, v_{\mathrm{vh}}^{\prime} \quad$ Poisson ratios for cross-anisotropic elastic soil

$\sigma_{\mathrm{a}}^{\prime} \quad$ axial effective stress, also vertical $\sigma_{z}^{\prime}$

$\sigma_{\mathrm{r}}^{\prime}$ radial effective stress, also horizontal $\sigma_{y}^{\prime}$

$\sigma_{\theta}^{\prime} \quad$ circumferential effective stress, also horizontal $\sigma_{x}^{\prime}$

$\phi_{\mathrm{cs}}^{\prime} \quad$ critical state angle of shearing resistance

$\phi_{\mathrm{r}}^{\prime} \quad$ residual angle of shearing resistance

\section{REFERENCES}

Addenbrooke, T. I., Potts, D. M. \& Puzrin, A. M. (1997). The influence of pre-failure stiffness on the numerical analysis of tunnel construction. Géotechnique 47, No. 3, 693-712, http://dx. doi.org/10.1680/geot.1997.47.3.693.

Anh-Minh, N. (2006). An investigation of the anisotropic stress-strain-strength characteristics of an Eocene clay. $\mathrm{PhD}$ thesis, Imperial College London, London, UK.

Arup (2007). Factual report: ground investigation at the Wixams, Bedford. London, UK: Arup \& Partners.

Brosse, A. (2012). Study on the anisotropy of British stiff clays using a hollow cylinder apparatus. $\mathrm{PhD}$ thesis, Imperial College London, London, UK.

Butcher, A. \& Lord, J. (1993). Engineering properties of the Gault Clay in and around Cambridge, UK. Proceedings of international symposium on geotechnical engineering of hard soils-soft rocks, Athens, Greece, pp. 405-416.

Butcher, A. P. \& Powell, J. M. M. (1995). The effects of geological history on the dynamic stiffness in soils. Proceedings of the 11th European conference on soil mechanics, Copenhagen, Denmark, vol. 1 , pp. $1.27-1.36$.

Cuccovillo, T. \& Coop, M. R. (1997). The measurement of local axial strains in triaxial tests using LVDTs. Géotechnique 47, No. 1, 167-171, http://dx.doi.org/10.1680/geot.1997. 47.1.167.
Gasparre, A. (2005). Advanced laboratory characterisation of London Clay. PhD thesis, Imperial College London, London, UK.

Gasparre, A., Nishimura, S., Coop, M. R. \& Jardine, R. J. (2007a). The influence of structure on the behaviour of London Clay. Géotechnique 57, No. 1, 19-31, http://dx.doi.org/10.1680/geot. 2007.57.1.19.

Gasparre, A., Nishimura, S., Anh-Minh, N., Coop, M. R. \& Jardine, R. J. (2007b). The stiffness of natural London Clay. Géotechnique 57, No. 1, 33-47, http://dx.doi.org/10.1680/geot. 2007.57.1.33.

Gasparre, A., Hight, D. W., Coop, M. R. \& Jardine, R. J. (2014). The laboratory measurement and interpretation of the smallstrain stiffness of stiff clays. Géotechnique 64, No. 12, 942-953, http://dx.doi.org/10.1680/geot.13.P.227.

Gibson, R. E. (1974). Analytical method in soil mechanics. Géotechnique 24, No. 2, 115-140, http://dx.doi.org/10.1680/ geot.1974.24.2.115

Hight, D. W., Gasparre, A., Nishimura, S., Anh-Minh, N., Jardine, R. J. \& Coop, M. R. (2007). Characteristics of the London Clay from the Terminal 5 site at Heathrow Airport. Géotechnique 57, No. 1, 3-18, http://dx.doi.org/10.1680/ geot.2007.57.1.3.

Hird, C. C. \& Pierpoint, N. D. (1997). Stiffness determination and deformation analysis for a trial excavation in Oxford Clay. Géotechnique 47, No. 3, 665-691, http://dx.doi.org/10.1680/ geot.1997.47.3.665.

Hosseini Kamal, R. (2012). Experimental study of the geotechnical properties of UK mudrocks. $\mathrm{PhD}$ thesis, Imperial College London, London, UK.

Hosseini Kamal, R., Coop, M. R., Jardine, R. J. \& Brosse, A (2014). The post-yield behaviour of four Eocene-to-Jurassic UK stiff clays. Géotechnique 64, No. 8, 620-634, http://dx.doi.org/ 10.1680/geot.13.P.043.

Jamiolkowski, M., Leroeuil, S. \& Lo Presti, D. C. F. (1991). Design parameters from theory to practice. Proceedings of Geo-coast' 91 international conference, Yokosuka, Japan, vol. 2, pp. 877-917.

Jamiolkowski, M., Lancellotta, R. \& Lo Presti, D. C. F. (1995). Remarks on the stiffness at small strains of six Italian clays In Pre-failure deformation of geomaterials (eds S. Shibuya, T. Mitachi and S. Miura), pp. 817-836. Rotterdam, the Netherlands: Balkema.

Jardine, R. J. (1985). Investigations of pile soil behaviour. $\mathrm{PhD}$ thesis, Imperial College, London, UK.

Jardine, R. J. (1992). Observations on the kinematic nature of soil stiffness at small strains. Soils Found. 32, No. 2, $111-124$.

Jardine, R. J. (2013). Advanced laboratory testing in research and practice: the 2nd Bishop Lecture. Geotech. Res. 1, No. 1, 2-31.

Jardine, R. J., Symes, M. J. \& Burland, J. B. (1984). The measurement of soil stiffness in the triaxial apparatus. Géotechnique 34, No. 3, 323-340, http://dx.doi.org/ 10.1680/geot.1984.34.3.323.

Jovičić, V. \& Coop, M. R. (1997). Stiffness of coarse-grained soils at small strains. Géotechnique 47, No. 3, 545-561, http://dx.doi.org/ 10.1680/geot.1997.47.3.545.

Kuwano, R. (1999). The stiffness and yielding anisotropy of sand. $\mathrm{PhD}$ thesis, Imperial College London, London, UK.

Kuwano, R. \& Jardine, R. J. (1998). Stiffness measurements in a stress path cell. In Pre-failure behaviour of geomaterials (eds R. J. Jardine, M. C. R. Davies, D. W. Hight, A. K. Smith and S. E. Stallebrass), pp. 391-395. London, UK: Thomas Telford.

Kuwano, R. \& Jardine, R. J. (2007). A triaxial investigation of kinematic yielding in sand. Géotechnique 57, No. 7, 563-580, http://dx.doi.org/10.1680/geot.2007.57.7.563.

Lings, M. L. (2001). Drained and undrained anisotropic elastic stiffness parameters. Géotechnique 51, No. 6, 555-565, http:// dx.doi.org/10.1680/geot.2001.51.6.555.

Lings, M. L., Pennington, D. S. \& Nash, D. F. T. (2000). Anisotropic stiffness parameters and their measurement in a stiff natural clay. Géotechnique 50, No. 2, 109-125, http://dx.doi.org/10.1680/ geot.2000.50.2.109.

Ng, C. W. W., Simpson, B., Lings, M. L. \& Nash, D. F. T. (1998). Numerical analysis of a multi-propped excavation in stiff clay. Can. Geotech. J. 35, No. 1, 115-130. 
Nishimura, S. (2006). Laboratory study of the anisotropy of natural London Clay. PhD thesis, Imperial College London, London, UK.

Nishimura, S., Minh, N. A. \& Jardine, R. J. (2007). Shear strength anisotropy of natural London Clay. Géotechnique 57, No. 1, 49-62, http://dx.doi.org/10.1680/geot.2007.57.1.49.

Parry, R. H. G. (1988). Short-term slipping of a shallow excavation in Gault Clay. Proc. Instn Civil Engrs 84, No. 1, 337-353.

Pennington, D. S., Nash, D. F. T. \& Lings, M. L. (1997). Anisotropy of $G_{0}$ shear stiffness in Gault clay. Géotechnique 47, No. 3, 391-398, http://dx.doi.org/10.1680/geot.1997.47.3.391.

Pierpoint, N. D. (1996). The prediction and back analysis of excavation behaviour in Oxford Clay. $\mathrm{PhD}$ thesis, University of Sheffield, Sheffield, UK.

Rampello, S. \& Viggiani, G. M. B. (2001). Pre-failure deformation characteristics of geomaterials. In Pre-failure deformation characteristics of geomaterials (eds M. Jamiolkowski, R. Lancellota and D. Lo-Presti), pp. 1279-1289. Lisse, the Netherlands: Swets and Zeitlinger.
Smith, P. R., Jardine, R. J. \& Hight, D. W. (1992). On the yielding of Bothkennar clay. Géotechnique 42, No. 2, 257-274, http://dx.doi. org/10.1680/geot.1992.42.2.257.

Tatsuoka, F. (2011). Laboratory stress--strain tests for developments in geotechnical engineering, 1st Bishop Lecture. In Proceedings of 5 th international symposium on deformation characteristics of geomaterials (IS-Seoul) (eds C-K. Chung, H-K. Kim, J-S. Lee, Y-H. Jung and D-S. Kim), vol. 1, pp. 3-53. Amsterdam, the Netherlands: IOS Press.

Viggiani, G. \& Atkinson, J. H. (1995). Stiffness of fine-grained soils at very small strains. Géotechnique 45, No. 2, 249-255, http://dx. doi.org/10.1680/geot.1995.45.2.249.

Vucetic, M. (1994). Cyclic threshold shear strains in soils. J. Geotech. Engng, ASCE 120, No. 12, 2208-2228.

Wilkinson, S. (2011). The microstructure of UK mudrocks. $\mathrm{PhD}$ thesis, Imperial College London, London, UK.

Zdravkovic, L. \& Jardine, R. J. (1997). Some anisotropic stiffness characteristics of a silt under general stress conditions. Géotechnique 47, No. 3, 407-438, http://dx.doi.org/10.1680/ geot.1997.47.3.407. 